\title{
Adding Latin America to the Global Projection Model
}

Jorge Canales Kriljenko,

Charles Freedman,

Roberto Garcia-Saltos,

Marianne Johnson, and Douglas Laxton 



\title{
IMF Working Paper
}

Western Hemisphere Department

Adding Latin America to the Global Projection Model ${ }^{1}$

\section{Prepared by Jorge Canales Kriljenko, Charles Freedman, Roberto Garcia-Saltos, Marianne Johnson, and Douglas Laxton}

Authorized for distribution by Robert Rennhack

April 2009

\begin{abstract}
This Working Paper should not be reported as representing the views of the IMF. The views expressed in this Working Paper are those of the author(s) and do not necessarily represent those of the IMF or IMF policy. Working Papers describe research in progress by the author(s) and are published to elicit comments and to further debate.

This is the fourth of a series of papers that are being written as part of a larger project to estimate a small quarterly Global Projection Model (GPM). The GPM project is designed to improve the toolkit to which economists have access for studying both own-country and cross-country linkages. In this paper, we add Latin American economies to a previously estimated small quarterly projection model of the US, Euro Area, and Japanese economies. The model is estimated with Bayesian techniques, which provide a very efficient way of imposing restrictions to produce both plausible dynamics and sensible forecasting properties.

JEL Classification Numbers: C51, E31, E52

Keywords: Macroeconomic Modeling, Bayesian Estimation, Monetary Policy Author's E-Mail Address: jcanaleskriljenko@,imf.org, Charles Freedman@carleton.ca, rgarciasaltos@,imf.org, mjohnson@,bankofcanada.ca

\footnotetext{
${ }^{1}$ Freedman is a Scholar in Residence in the Economics Department, Carleton University, Ottawa, Canada. The authors wish to thank Olivier Blanchard, Charles Collyns, Ondra Kamenik, Robert Reenhack and our colleagues at other policymaking institutions for encouraging us to do this work. We also gratefully acknowledge the invaluable support of Heesun Kiem, Ioan Carabenciov, Susanna Mursula, Carolina Saizar, Ben Sutton, and Laura Leon. The views expressed here are those of the authors and do not necessarily reflect the position of the International Monetary Fund. Correspondence: rgarciasaltos@imf.org, jcanaleskriljenko@,imf.org
} 


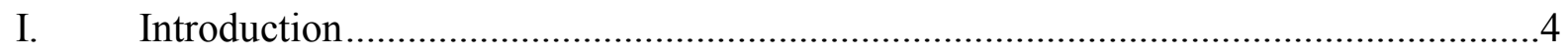

II. Benchmark Model................................................................................................

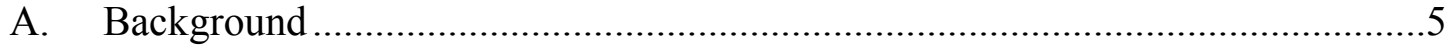

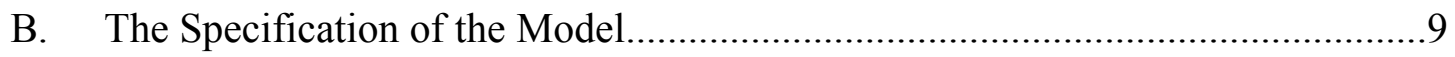

B.1 Observable variables and data definitions ........................................ 9

B.2 Stochastic processes and model definitions ........................................10

B.3 Behavioral equations..................................................................... 12

B.4 Cross correlations of disturbances ................................................. 15

III. Extending the Model to Include Financial-Real Linkages .......................................16

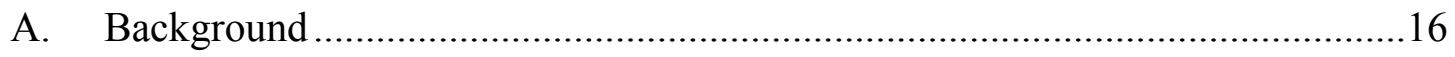

B. Model Specification Incorporating the US Bank Lending

Tightening Variable

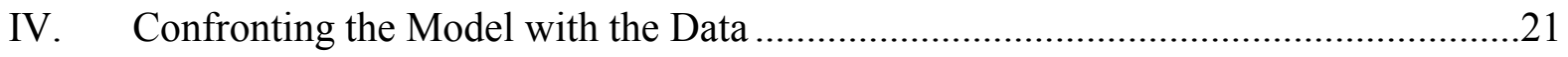

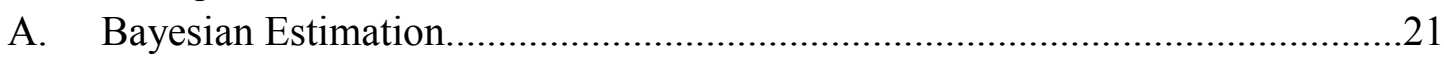

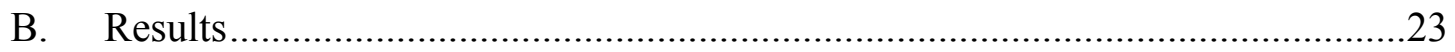

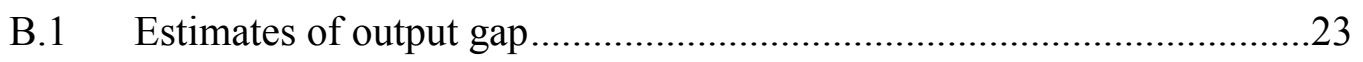

B.2 Estimates of coefficients ..........................................................23

B.3 Estimates of standard deviation of structural shocks and cross correlations .................................................................26

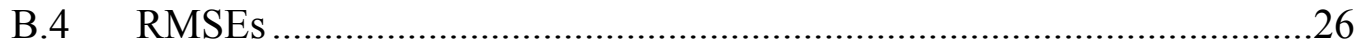

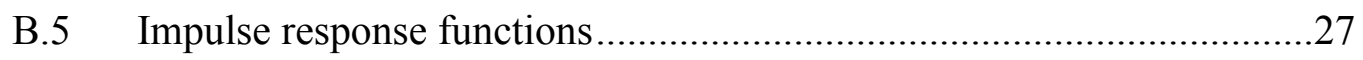

B.6 Historical variance decomposition..................................................28

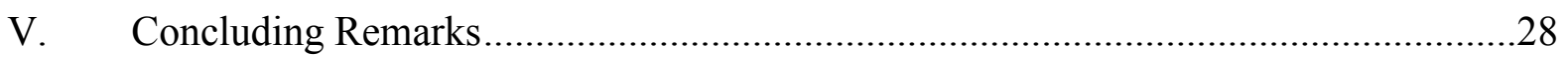

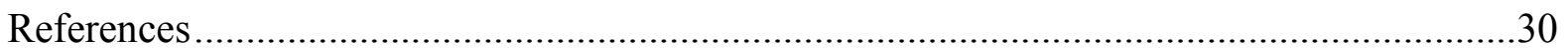

Appendix Tables

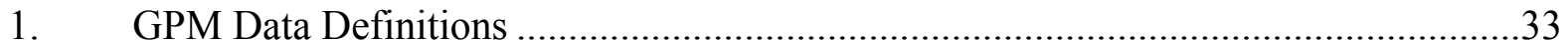

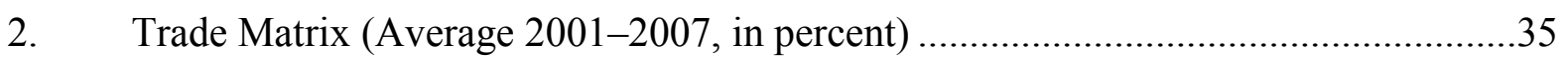

Text Tables

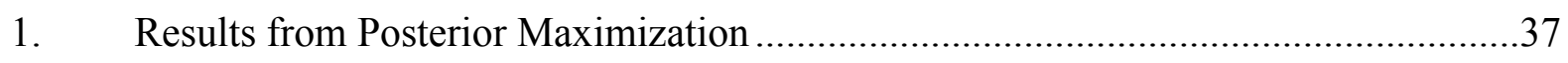

2. Results from Posterior Parameters (Standard Deviation of Structural Shocks) ..........41

3. Results from Posterior Parameters (Correlation of Structural Shocks) ......................42

4. Root Mean Squared Errors.............................................................................43 


\section{Figures}

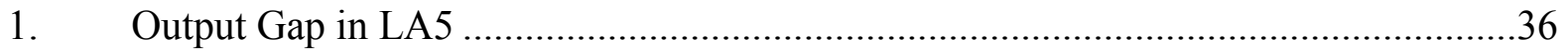

2. Estimated Parameters in the Output Gap Equation...................................................38

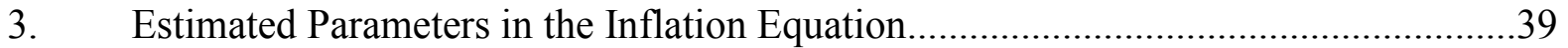

4. Estimated Parameters in the Monetary Policy Rule ....................................................40

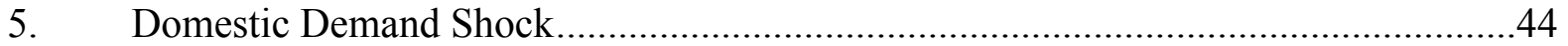

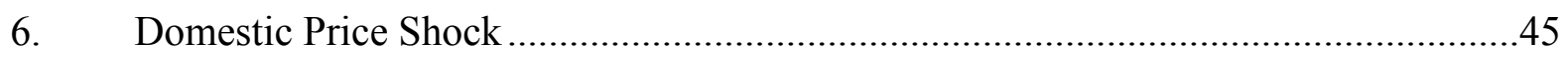

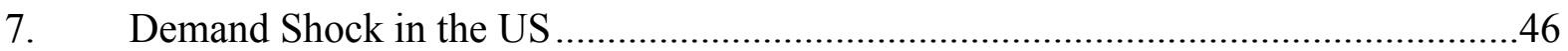

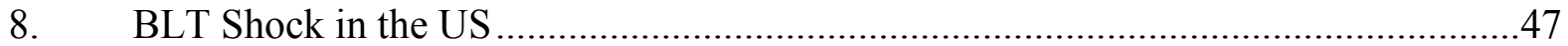

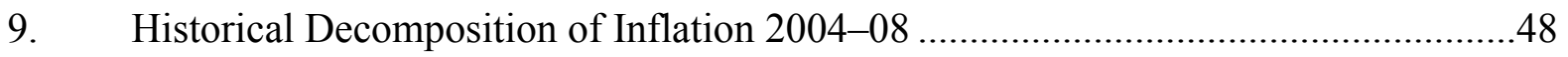




\section{Introduction}

This study is the fourth of a series of studies designed to develop a full global projection model. The first study in the series, "A small quarterly projection model of the US economy" (Carabenciov and others, 2008a), set out a closed economy version of the model and applied it to the US economy using Bayesian estimation techniques. It incorporated a financial variable for the US economy, enabling us to see the effects of changes in this variable on US output and inflation. The second in the series, "A small quarterly multi-country projection model" (Carabenciov and others, 2008b), extended the model to an open economy. It set out a small quarterly projection model of the US, euro area, and Japanese economies to illustrate the way that such models can be used to understand past economic developments and to forecast future developments in a multi-country setting. It also incorporated the financial variable for the US economy, enabling us to see the effects of changes in this variable on the US economy and on the other economies. The third paper in the series, "A Small Quarterly Multi-Country Projection Model With Financial-Real Linkages and Oil Prices" (Carabenciov and others, 2008c), added oil prices to the three country model. This permitted us to examine the effects of temporary and permanent shocks to the level and growth rate of oil prices on the three economies.

In this paper, we add the aggregate of the five inflation-targeting Latin American economies (Brazil, Chile, Colombia, Mexico and Peru) to the previously-estimated three country model without oil presented in Carabenciov and others (2008b). These five economies represent about 75 percent of total Latin American output. Although each of these Latin American economies was added to the three country model separately, in this paper we focus on the addition of an aggregate of the five countries (henceforward termed either Latin America or LA5). The data for LA5 are based on the weighted sum or weighted average of the data for the five economies, with weights based on their relative size using purchasing-power-parity based GDP measures.

Using a multicountry framework in this context is warranted given the large increase in trade and financial flows experienced by these countries in recent years. The extended model allows us to examine the effects on these countries of demand and supply shocks in their own area, and also permits us to examine the effects on the Latin American economies of shocks in the world's largest economies. From a practical point of view, using this framework helps us to 
identify the nature of the inflation spike experienced by these countries in early 2008 .

While the emphasis in this paper is on the results of the extended model, a companion "how to" paper is currently being written that will present a guide to central banks in other countries that would like to add a small model of their own economy to the model of the three large economies. Among the issues addressed in that paper will be how to add new countries to the basic large economy model in a way that is most efficient.

The studies completed thus far are preparatory to the next steps in our research agenda - first, to incorporate a more sophisticated oil sector with global demand and supply for oil; second, to extend the model to include financial variables in countries other than the United States; and third, to develop a small quarterly Global Projection Model (GPM) that will integrate a number of large and small country models into a single global model that can be used for global economic projections. Such a model would include the United States, the euro area, Japan, oil exporters, China, emerging Asia excluding China, and the rest of the world.

\section{Benchmark Model}

\section{A. Background}

In recent years, the IMF has developed two main types of macroeconomic models - dynamic stochastic general equilibrium (DSGE) models and small quarterly projection models (QPMs) - that it has used to analyze economic behavior and to forecast future developments. The DSGE models are based on theoretical underpinnings and have been found to be very useful in analyzing the effects of structural changes in the economy, as well as the effects of longer-term developments such as persistent fiscal deficits and current account deficits. ${ }^{1}$ And multi-country variants of these models have allowed researchers to analyze the effects of shocks in one country on economic variables in other countries. The small quarterly projection models use four or five behavioral equations to characterize the macroeconomic structure of an economy in a way that is both easy to use by modelers and comprehensible to policymakers. They focus on the key macroeconomic variables in the economy - typically

\footnotetext{
${ }^{1}$ See Botman and others (2007) for a summary of the applications using these models.
} 
output, inflation, a short-term interest rate, and sometimes the exchange rate and/or the unemployment rate. By virtue of their relatively simple and readily understandable structure, they have been used for forecasting and policy analysis purposes in central banks and by country desks in the IMF. ${ }^{2}$ In the past, the parameters of such models have been calibrated on the basis of the knowledge of country experts of the economic structure of the country being studied and that of similar countries.

In the series of papers cited earlier and in this paper, a number of important elements or extensions are being applied to the basic model. First, in all the papers in the series, Bayesian techniques are used to estimate the parameters of the model. Bayesian methods allow researchers to input their priors into the model and then to confront them with the data, in order to determine whether their priors are more or less consistent with the data. Although regime shifts in recent years (most notably, the anchoring of inflation expectations to a formal or informal target in many countries) limit the time series to relatively short periods, the estimation approach taken in these papers will be increasingly useful over time as the lengths of usable time series are extended.

Second, the number of countries in the model has continually been expanded. The first paper examined the US economy. In the second and third papers, we expanded the model to three economies - United States, the Euro area, and Japan. This paper adds Latin America to the three economy model. In a future paper, the small quarterly models of a number of countries (United States, the euro area, Japan, oil-exporting countries, China, emerging Asia excluding China, and the rest of the world) will be integrated into a small quarterly Global Projection Model (GPM) that covers the entire world economy, which will enable researchers to analyze the effects on a number of countries of shocks in one country and of global shocks. Moreover, the model will be programmed in such way that researchers will be able to add other countries to the model in a relatively straightforward manner. Such models will give forecasters a new tool to assist them in preparing worldwide forecasts and in carrying out alternative policy simulations in the global context. There is strong demand for such an empirically based multi-country model, both for IMF surveillance work and for helping central bank forecasters

\footnotetext{
${ }^{2}$ See Berg, Karam, and Laxton (2006a,b) for a description of the basic model as well as Epstein and others (2006) and Argov and others (2007) for examples of applications and extensions. Currently, Fund staff are using the model to support forecasting and policy analysis and to better structure their dialogue with member countries. A number of inflation-targeting central banks have used similar models as an integral part of their Forecasting and Policy Analysis Systems - see Coats, Laxton and Rose (2003) for a discussion about how such models are used in inflation-targeting countries.
} 
to assess the external environment in preparing their projections. Large-scale DSGE models show promise in this regard, but we are years away from developing empirically-based multi-country versions of these models. While global VARs (GVARs) have been developed for forecasting exercises, they are not very useful for policy analysis because they lack the identification restrictions necessary to obtain plausible impulse response functions or to properly identify policy reaction functions.

Third, given the importance in recent years and at present of financial-real linkages, we have been experimenting with financial variables that might be helpful in explaining economic developments and in forecasting future movements of the economy. Thus far, we have used a single financial variable, a US bank lending tightening measure $\left(\mathrm{BLT}_{u s}\right)$, which contributed importantly to the explanation of movements of the US economy over the sample period and also improved out-of-sample forecasting. In future papers we will broaden the use of financial variables to include a number of financial measures of risk in the United States and other countries.

Fourth, commodity prices are being incorporated into the model. In the third paper we extended the model to include oil prices. On a number of occasions since 1973, sharp increases or decreases in oil prices have had an important effect on output and inflation in the major economies. And the very steep increase in oil prices in the most recent episode raised questions about the severity of the downturn in economic activity that was likely to result, and the extent to which the oil-induced increase in the headline inflation rate was likely to spread to inflation expectations and broader inflation pressures. Modeling the linkages between oil prices and output and inflation should therefore be helpful in assessing the economic outlook in the major industrial economies. Future versions of the model will include more sophisticated models of the oil market. They could also include other commodity prices that are relevant for a specific country or group of countries.

Fifth, in this paper, we extend the model (without oil prices) to include the aggregate of the five inflation-targeting Latin American economies. Although it would be possible to estimate the model jointly for the three large economies and the aggregate Latin American economy (LA5), such an approach to estimation of the model would be very time consuming and would render it difficult to experiment with the coefficients of the additional economy. Instead, we treat the estimates for the three large economies taken from the previously-estimated multicountry model without oil (Carabenciov and others, 2008b) as given, and generate 
estimates for only the newly-added Latin American aggregate economy. Implicitly, this assumes that adding a new economy will have little influence on the estimates of the coefficients and of the standard deviations and cross-correlations of structural shocks for the three large economies. Also, in estimating the LA5 parameters, we take as observable variables the estimated latent variables in the MCM model, including output gaps for the United States, the euro area, and Japan.

There are three main approaches to using such an estimated model for policy simulations and forecasting. The first way, which would be appropriate for very small economies, leaves the specification of variables in the large economies unchanged. This assumes that any change in output or inflation in the additional economy has no effect on any of the endogenous variables in the large economies. That is, causation in such a version of the model is totally unidirectional, with large economy shocks affecting the small economy but not vice versa. The second approach, which would be appropriate for somewhat larger economies and for the aggregate of a number of economies and is used in this paper, would respecify certain external variables in the equations for the large economies to include movements in the relevant variables in the additional economy. For example, the foreign activity gap variables that affect the output gaps in the large countries would include (with appropriate weight) the output gap in the additional economy. Similarly, the effective exchange rate variable that enters into both the output gap variables of the large countries and their inflation variables would be respecified to incorporate (again with appropriate weight) the exchange rate in the additional economy. In this approach, causation operates in both directions with shocks in the large countries affecting the additional economy, and shocks in the additional economy affecting the large countries, albeit with a weight that reflects its typically smaller size. In sum, although this second approach does not allow the addition of an extra economy to the model to affect the estimated values of the parameters of the large countries, it does allow shocks in the additional economy to affect the endogenous variables in the large countries. It thus takes an intermediate position between the first approach, in which the additional country has no influence on the large economies either in estimation or simulation, and the third approach, in which the addition of another economy to the model would be allowed to affect both the estimated parameters of the large countries and their behavior following a shock to the additional economy. 


\section{B. The Specification of the Model}

This section of the paper sets out the model that describes the behavior in both the large economies and the additional economy. The small generic open economy model describes the joint determination of output, unemployment, inflation, a short-term interest rate and the exchange rate. The model is fundamentally a gap model, in which the gaps of the variables from their equilibrium values play the crucial role in the functioning of the system. A number of definitions and identities are used to complete the model. We present the model specification for a single country labelled $i$. The specification for other countries will be very similar, although the priors for the coefficient estimates and for the standard deviations and cross correlations of the structural shocks will differ across economies on the basis of expert knowledge of those economies. In the next section of the paper, we will expand the model to include the US BLT variable.

\section{B.1 Observable variables and data definitions}

The benchmark model has 5 observable variables for each economy. ${ }^{3}$ These are real GDP, the unemployment rate, CPI inflation, a short-term interest rate, and the exchange rate. ${ }^{4}$ We use capital letters for the variables themselves and small letters for the gaps between the variables and their equilibrium values. Thus, we define $\mathrm{Y}$ as 100 times the log of real GDP, $\bar{Y}$ as 100 times the log of potential output and lowercase $y$ as the output gap in percentage terms ( $y=Y$ $-\bar{Y})$. Similarly, we define the unemployment gap, u, as the difference between the actual unemployment rate $(U)$ and the equilibrium unemployment rate or NAIRU, $\bar{U}$. We define the quarterly rate of inflation at annual rates $(\pi)$ as 400 times the first difference of the log of the CPI. In addition, we define the year-on-year measure of inflation $(\pi 4)$ as 100 times the difference of the log of the CPI in the current quarter from its value four quarters earlier. The nominal interest rate is $\mathrm{I}$, the real interest rate is $\mathrm{R}$, the nominal exchange rate vis-à-vis the US dollar is $\mathrm{S}$, and the $\log$ of the real exchange rate vis-à-vis the US dollar is $Z$. The gap between the real exchange rate, $\mathrm{Z}$, and its equilibrium value, $\bar{Z}$, is denoted as $\mathrm{z}$.

\footnotetext{
${ }^{3}$ Data definitions are provided in the appendix to this paper.

${ }^{4}$ More accurately, each non-U.S. economy has an exchange rate vis-à-vis the U.S. dollar. So if there are N economies in the model, there will be N-1 exchange rates.
} 


\section{B.2 Stochastic processes and model definitions}

A major advantage of Bayesian methods is that it is possible to specify and estimate fairly flexible stochastic processes. In addition, unlike classical estimation approaches, it is possible to specify more stochastic shocks than observable variables, which is usually necessary to prevent the model from making large and systematic forecast errors over long periods of time. For example, an important ingredient in specifying a forecasting model, as we will see in this section, is allowing for permanent changes in the underlying estimates of the equilibrium values for potential output and for the equilibrium unemployment rate.

We assume that there can be shocks to both the level and growth rate of potential output. The shocks to the level of potential output can be permanent, while the shocks to the growth rate can result in highly persistent deviations in potential growth from long-run steady-state growth. In equation $1 \overline{\mathrm{Y}}$ is equal to its own lagged value plus the quarterly growth rate ( $\overline{\mathrm{g}} / 4)$ plus a disturbance term $\left(\varepsilon^{\bar{Y}}\right)$ that can cause permanent level shifts in potential GDP.

$$
\bar{Y}_{i, t}=\bar{Y}_{i, t-1}+g_{i, t}^{\bar{Y}} / 4+\varepsilon_{i, t}^{\bar{Y}}
$$

As shown in equation 2 , in the long run the growth rate of potential GDP, $\mathrm{g}^{\bar{Y}}$, is equal to its steady-state rate of growth, $\mathrm{g}^{\bar{Y}}$ ss . But it can diverge from this steady-state growth following a positive or negative value of the disturbance term $\left(\varepsilon^{g^{\bar{Y}}}\right)$, and will return to $\mathrm{g}^{\bar{Y} s s}$ gradually, with the speed of return based on the value of $\tau$.

$$
g_{i, t}^{\bar{Y}}=\tau_{i} g_{i}^{\bar{Y}_{s s}}+\left(1-\tau_{i}\right) g_{i, t-1}^{\bar{Y}}+\varepsilon_{i, t}^{g^{\bar{Y}}}
$$

A similar set of relationships holds for the equilibrium or NAIRU rate of unemployment. $\bar{U}$ is defined in equation 3 as its own past value plus a growth term $\mathrm{g}^{\bar{U}}$ and a disturbance term $\left(\varepsilon^{\bar{U}}\right)$. And in equation $4, \mathrm{~g}^{\bar{U}}$ is a function of its own lagged value and the disturbance term $\left(\varepsilon^{g^{\bar{U}}}\right)$. Thus, the NAIRU can be affected by both level shocks and persistent growth shocks.

$$
\begin{gathered}
\bar{U}_{i, t}=\bar{U}_{i, t-1}+g_{i, t}^{\bar{U}}+\varepsilon_{i, t}^{\bar{U}} \\
g_{i, t}^{\bar{U}}=\left(1-\alpha_{i, 3}\right) g_{i, t-1}^{\bar{U}}+\varepsilon_{i, t}^{g \bar{U}}
\end{gathered}
$$

Equation 5 defines the real interest rate, $\mathrm{R}$, as the difference between the nominal interest rate, I, and the expected rate of inflation for the subsequent quarter. 


$$
R_{i, t}=I_{i, t}-\pi_{i, t+1}
$$

Equation 6 defines $r$, the real interest rate gap, as the difference between $\mathrm{R}$ and its equilibrium value, $\bar{R}$.

$$
r_{i, t}=R_{i, t}-\bar{R}_{i, t}
$$

Equation 7 defines $\bar{R}$, the equilibrium real interest rate, as a function of the steady-state real interest rate, $\bar{R}^{s s}$. It has the ability to diverge from the steady state in response to a stochastic $\operatorname{shock}\left(\varepsilon^{\bar{R}}\right)$.

$$
\bar{R}_{i, t}=\rho_{i} \bar{R}_{i}^{s s}+\left(1-\rho_{i}\right) \bar{R}_{i, t-1}+\varepsilon_{i, t}^{\bar{R}}
$$

Equation 8 defines $Z_{i}$, the $\log$ of the real exchange rate in country $i$, as equal to 100 times the $\log$ of the nominal exchange rate, $\mathrm{S}_{i}$ (defined as the number of units of local currency in country i vis-à-vis the US dollar), times the CPI $\left(\mathrm{P}_{u s}\right)$ in the United States, divided by the CPI in country $\mathrm{i}\left(\mathrm{P}_{i}\right)$. An increase in $Z_{i}$ is thus a real depreciation of currency i vis-à-vis the US dollar.

$$
Z_{i, t}=100 * \log \left(S_{i, t} P_{u s, t} / P_{i, t}\right)
$$

The change in the log of the real exchange rate is shown in equation 9 as 100 times the change in the log of the nominal exchange rate less the difference between the quarterly inflation rates in country $i$ and the United States. It is therefore approximately equal to the change in percentage terms for small changes.

$$
\Delta Z_{i, t}=100 \Delta \log \left(\mathrm{S}_{i, t}\right)-\left(\pi_{i, t}-\pi_{u s, t}\right) / 4
$$

Equation 10 defines the expected real exchange rate for the next period, $Z^{e}$, as a weighted average of the lagged real exchange rate and the 1-period model-consistent solution of the real exchange rate.

$$
Z_{i, t+1}^{e}=\phi_{i} Z_{i, t+1}+\left(1-\phi_{i}\right) Z_{i, t-1}
$$

Equation 11 defines the real exchange rate gap, $\mathrm{z}$, as equal to the log of the real exchange rate minus the log of the equilibrium real exchange rate, $\bar{Z}$.

$$
z_{i, t}=Z_{i, t}-\bar{Z}_{i, t}
$$

Equation 12 defines the equilibrium real exchange rate, $\bar{Z}$, as equal to its lagged value plus a 
disturbance term, $\varepsilon^{\bar{z}}$.

$$
\bar{Z}_{i, t}=\bar{Z}_{i, t-1}+\varepsilon_{i, t}^{\bar{z}}
$$

\section{B.3 Behavioral equations}

Equation 13 is a behavioral equation that relates the output gap (y) to its own lead and lagged values, the lagged value of the gap in the short-term real interest rate (r), the output gaps in its trading partners, the effective real exchange rate gap, and a disturbance term $\left(\varepsilon^{y}\right)$. The foreign output gap term is defined as a weighted average of the lagged foreign output gaps, ${ }^{5}$ where the weights $\left(\omega_{i, j, 5}\right)$ are the ratios of the exports of country $i$ to country $j$ to total exports of country $i$ to all the countries in the model. This weighted foreign output gap variable is thus a form of activity variable, with the weights imposed on the basis of past data. The effective real exchange rate gap variable in the equation is a weighted average of the real exchange rate gaps of the foreign countries with which economy i trades. ${ }^{6}$. In this case, the weights $\left(\omega_{i, j, 4}\right)$ are the ratio of the sum of exports and imports of country $i$ with country $j$ to the sum of exports and imports with all the countries in the model and are also imposed on the basis of the data.

$$
y_{i, t}=\beta_{i, 1} y_{i, t-1}+\beta_{i, 2} y_{i, t+1}-\beta_{i, 3} r_{i, t-1}+\beta_{i, 4} \sum_{j} \omega_{i, j, 4} z_{i, j, t-1}+\beta_{i, 5} \sum_{j} \omega_{i, j, 5} y_{j, t-1}+\varepsilon_{i, t}^{y}
$$

All variables in this equation are expressed as deviations from their equilibrium values. The own-lag term allows for the inertia in the system, and permits shocks to have persistent effects. The lead term allows more complex dynamics and forward-looking elements in aggregate demand. The real interest rate term and the real exchange rate term provide the crucial direct and indirect links between monetary policy actions and the real economy. And the activity variable allows for the direct trade links among the various economies.

The specification of the real exchange rate gap variables (z) is somewhat complex in a multi-country model. Since all the exchange rate variables are defined in terms of the US dollar, the bilateral real exchange rate gaps for all country pairs except those involving the

\footnotetext{
${ }^{5}$ In a future version of the model, we plan to use a weighted average of lagged and contemporaneous foreign output gaps in the domestic output gap equation. Japan.

${ }^{6}$ The way that the shares are computed assumes that LA5 trades only with the United States, the euro area and
} 
United States should be in relative terms. Consider, for example, the euro area output gap equation. If the euro area exchange rate were overvalued by $5 \%$ (that is, its $\mathrm{z}$ is minus $5 \%$ ) and if the yen exchange rate were undervalued by $10 \%$ (that is, its $\mathrm{z}$ is plus $10 \%$ ), then the euro is overvalued by $15 \%$ vis-à-vis the yen, and the $z_{e u, j a}$ enters the euro area output gap equation as $\mathrm{z}_{e u}-\mathrm{z}_{j a}$, or $-15 \%$. In contrast, only $\mathrm{z}_{e u}$ has to be inserted in the euro area output gap equation as the real exchange rate gap vis-à-vis the US dollar. In the US output gap equation, one can either use the simple $\mathrm{z}$ variables and expect $\beta_{u s, 4}$ to be negative, or, alternatively, use the negatives of the $\mathrm{z}$ variables and expect $\beta_{u s, 4}$ to have the same positive sign as all the other $\beta_{i, 4}$ coefficients. For simplicity, we have chosen to do the latter. ${ }^{7}$

Equation 14 is the inflation equation, which links inflation to its past value and its future value, the lagged output gap, the change in the effective exchange rate of the country (to capture exchange rate pass through), and a disturbance term $\left(\varepsilon^{\pi}\right){ }^{8}$ The size of $\lambda_{1}$ measures the relative weight of forward-looking elements and backward-looking elements in the inflation process. The backward-looking elements include direct and indirect indexation to past inflation and the proportion of price setters who base their expectations of future inflation on actual past rates of inflation. The forward-looking element relates to the proportion of price setters who base their expectations on model-consistent estimates of future inflation. The output gap is the crucial variable linking the real side of the economy to the rate of inflation.

The rate of inflation is also influenced by the change in the effective real exchange rate of country i. As in the case of the output gap equation, the treatment of exchange rate movements is somewhat complex. Since the real exchange rates are all based on the US dollar, the change in the bilateral real rate of exchange of currency i relative to currency $j$ (where neither i nor $\mathrm{j}$ is the United States) is defined as the change of currency i relative to the US dollar minus the change of currency $\mathrm{j}$ relative to the US dollar, or $\Delta Z_{i}-\Delta Z_{j}$, with a positive value being a real depreciation of currency $i$ vis-à-vis currency $j$. Where $j$ is the United States, the relevant variable is $\Delta Z_{i}$. The weights on the changes in the bilateral real exchange rates are based on imports of country $i$ from country $j$ and the coefficient $\lambda_{i, 3}$ is expected to be positive. For the US inflation equation, the change in the real exchange rate

\footnotetext{
${ }^{7}$ Alternatively, one can code the real exchange rate gap of the United States versus country $i$ in the same way as the other real exchange rate gaps, i.e., as $\mathrm{z}_{u s}-\mathrm{z}_{i}$, and then define $\mathrm{z}_{u s}$ to be equal to zero.

${ }^{8}$ As was the case in the earlier multi-country paper, the disturbance to the inflation equation was entered with a negative sign in order to facilitate the estimation of the cross correlations.
} 
variables can be entered as $\Delta Z_{i}$ and $\lambda_{u s, 3}$ would be expected to be negative, or as $-\Delta Z_{i}$, with $\lambda_{u s, 3}$ expected to be positive. We have chosen to do the latter.

$$
\pi_{i, t}=\lambda_{i, 1} \pi 4_{i, t+4}+\left(1-\lambda_{i, 1}\right) \pi 4_{i, t-1}+\lambda_{i, 2} y_{i, t-1}+\lambda_{i, 3} \sum_{j} \omega_{i, j, 3} \Delta Z_{i, j, t}-\varepsilon_{i, t}^{\pi}
$$

Equation 15 is a Taylor-type equation that determines the short-term nominal interest rate (which can be interpreted either as the policy rate, as we do in this paper for the United States, or as a short-term market interest rate that is closely linked to the policy rate, as we do for the other two large economies, or as a mixture of policy rates and closely related money market rates, as is the case for the five Latin American economies). It is a function of its own lag (a smoothing device for the movement of short-term rates) and of the central bank's responses to movements of the output gap and to the deviation of the expected inflation rate from its target. More precisely, the central bank aims at achieving a measure of the equilibrium nominal interest rate over the long run (the sum of the equilibrium real interest rate and expected inflation over the four quarters starting the previous quarter), but adjusts its rate in response to deviations of the expected year-on-year rate of inflation three quarters in the future from the inflation target $\pi^{t a r}$ and to the current output gap. ${ }^{9}$ The equation also includes a disturbance term $\left(\varepsilon^{I}\right)$ to allow for central bank interest rate actions that are not exactly equal to those indicated by the equation.

$$
I_{i, t}=\left(1-\gamma_{i, 1}\right)\left[\bar{R}_{i, t}+\pi 4_{i, t+3}+\gamma_{i, 2}\left(\pi 4_{i, t+3}-\pi_{i}^{t a r}\right)+\gamma_{i, 4} y_{i, t}\right]+\gamma_{i, 1} I_{i, t-1}+\varepsilon_{i, t}^{I}
$$

Equation 16 is a version of uncovered interest parity (or UIP), in which the difference between the real exchange rate of currency $i$ and its expected value the following quarter (multiplied by 4 to transform the quarterly rate of change to an annual rate of change in order to make it comparable to the interest rate differentials) is equal to the difference between the real interest rate in country $i$ and its counterpart in the United States less the difference in the equilibrium real interest rates in the two countries. The latter is equivalent to the equilibrium risk premium. Thus, if the real interest rate in country $i$ is greater than that in the United States, this would be a reflection of one of two possibilities or a combination of the two-either the currency i real exchange rate is expected to depreciate over the coming period

\footnotetext{
${ }^{9}$ The use of the rate of inflation three quarters in the future follows Orphanides (2003).
} 
( $Z^{e}$ is higher than $Z$ ), or the equilibrium real interest rates in the two countries differ because of a risk premium on yields of country $i$ assets denominated in the i currency. There is also a disturbance term, $\varepsilon^{Z-Z^{e}}$, in the equation. The model differs from Dornbusch's (1976) overshooting model insofar as $Z^{e}$ is not fully model consistent, being partly a function of the past levels of the real exchange rate (as shown in equation 10). Note that there are i-1 UIP equations in the model, with no such equation necessary in the US block of equations. ${ }^{10}$

$$
4\left(Z_{i, t+1}^{e}-Z_{i, t}\right)=\left(R_{i, t}-R_{u s, t}\right)-\left(\bar{R}_{i, t}-\bar{R}_{u s, t}\right)+\varepsilon_{i, t}^{Z-Z^{e}}
$$

Equation 17 provides a dynamic version of Okun's law where the unemployment gap is a function of its lagged value, the contemporaneous output gap and a disturbance term $\left(\varepsilon^{u}\right)$.

$$
u_{i, t}=\alpha_{i, 1} u_{i, t-1}+\alpha_{i, 2} y_{i, t}+\varepsilon_{i, t}^{u}
$$

This last equation does not play a very important role in the model but is used to help measure the output gap in real time by exploiting the correlation between changes in the output gap and contemporaneous and future changes in the unemployment gap.

\section{B.4 Cross correlations of disturbances}

The model is also able to incorporate cross correlations of error terms. There are two cross correlations to the LA5 disturbances specified in this version of the model. The first involves a correlation between $\varepsilon^{\bar{Y}}$ and $\varepsilon^{\pi}$. This implements in the model the notion that a positive supply shock to the level of potential output puts downward pressure on costs and prices. This correlation structure is used to roughly mimic the impulse response functions (IRFs) that have been estimated in DSGE models of the US economy and provides an example of how the dynamics of smaller semi-structural models can embody some of the insights from our deeper structural models - see Juillard and others (2007, 2008).

The second cross correlation involves a positive correlation between $\varepsilon^{g^{\bar{Y}}}$ and $\varepsilon^{y}$. The basic

\footnotetext{
${ }^{10}$ While the economics of the UIP equation is most easily understood as expressed in the text, the coding of the model is as follows: $\left(R_{i, t}-R_{u s, t}\right)=4\left(Z_{i, t+1}^{e}-Z_{i, t}\right)+\left(\bar{R}_{i, t}-\bar{R}_{u s, t}\right)+\varepsilon_{i, t}^{R_{i}-R_{u s}}$. The only difference between the two versions is that the impulse response function for shocks to this equation would reflect the form of the disturbance shown in this footnote, which is the negative of the disturbance shown in the text.
} 
idea is that a positive shock to potential output growth that is expected to persist for a considerable period of time will be associated with an increase in expected permanent income, which will raise spending by households even before the level of potential output increases. Similarly, businesses will be motivated to increase their investment spending on the basis of the expected faster growth in potential output. Thus, aggregate demand and actual output will rise before potential output and there will be an increase in the output gap as a result of the shock to the growth rate of potential output.

\section{Extending the Model to Include Financial-Real Linkages}

\section{A. Background}

For much of the postwar period, downturns in business cycles were precipitated mainly by increases in interest rates initiated by central banks in response to periods of excess demand that gave rise to inflation pressures. Indeed, in some countries (the United Kingdom being a prominent example), actions of the fiscal and monetary authorities were considered to have brought about a stop-go economy, in which policy switched periodically back and forth between an emphasis on unemployment and economic growth, on the one hand, and an emphasis on inflation, on the other. When the economy was weak, policy eased, giving rise to expansionary pressures. When these pressures were sufficiently strong and inflation became the overriding concern, policy was tightened so that the slowing or contraction of the economy would put downward pressure on inflation and prevent it from getting out of hand.

Such policy-induced slowdowns of the economy persisted from the 1950s into the 1990s, with virtually every downturn preceded by inflationary pressures and a resulting tightening of monetary policy. However, this central bank tightening explanation cannot account for the economic slowdown of the early part of this decade, or of the current slowdown of the US and other economies, since inflation pressures and interest rate increases were evidently not the main reason for these downturns. In the context of the apparent linkages between financial developments and the real economy, driven in part through asset price movements, attention has increasingly turned to the ways in which financial developments can affect the real 
economy. This interest has been aided by the development of theoretical models to describe and explain these linkages, in particular the financial accelerator mechanism. ${ }^{11}$

In our view, the more traditional types of models that allow central bank actions to play a major role in business cycle developments are still needed to explain much of the postwar period. However, the developments over the last decade or so require an extension to those models that have placed central bank actions at the center of the business cycle (and particularly for the downturns). The key factors in these most recent developments, and to a much lesser extent in earlier developments, are the financial developments that have interacted with the real side of the economy in what has come to be called financial-real linkages. ${ }^{12}$

There are many different variants of financial-real linkages. Some refer to developments in financial institutions, while others focus on developments in financial markets. Within the financial institution sector, some relate to the behavior of banks and other financial institutions in dealing with perceptions of the changing risk situation facing their customers or changing attitudes to risk on their own part, while others relate to situations in which banks' capital positions have deteriorated. In the case of financial markets, there have been cases in which liquidity has seized up and prevented potential borrowers from issuing debt, and other cases in which actual or perceived pressures on the balance sheets of lenders and/or borrowers have been the origin of the inability of the financial markets to carry out their normal intermediation functions.

What does this imply for macro modeling? Consider first financial accelerators. As far as financial accelerator models are concerned, there can be an endogenous element in which the business cycle leads to increases and decreases of collateral values and hence to the ability to access funding, and an exogenous element in which exogenous shocks to asset values result in changes in the ability of borrowers to obtain financing. While the former can typically be captured to a considerable extent by interest rate movements, it will be important to try to model the latter. One issue that requires careful attention in structural DSGE models is whether financial institutions ration credit on the basis of collateral values (such as maximum

\footnotetext{
${ }^{11}$ See, for example, Bernanke and Gertler (1995). Interestingly, the perceived structural change in the way the economy operates has given rise to renewed interest in models of the business cycle from the interwar period in which real factors and financial factors other than central bank actions played a key role. See Laidler (2003).

${ }^{12}$ More detail on the postwar history of financial-real linkages can be found in the three earlier papers in this series.
} 
loan-to-value ratios) or simply tighten terms and conditions on the loans that they are prepared to extend. A second type of financial-real linkage relates to the capital position of financial institutions (most importantly banks) and how it affects the willingness of financial institutions to extend loans. A third type of linkage relates to whether financial markets are functioning normally or are facing either liquidity difficulties or problems in evaluating risks. All the episodes that were listed above and the economic behavior patterns underlying them raise the question of whether financial-real linkages should be part of the central macro model or should be modeled via satellite models. Should they feed into the forecast in normal circumstances or only in unusual episodes? And, if the latter, can they be treated as a form of regime shift?

In this and future papers, we will attempt to integrate financial-real linkages into the type of model described earlier. ${ }^{13}$ There a number of advantages to using a small model in trying to understand and model the role of the linkages for macro economic behavior. First of all, the insights that have been developed in more complex DSGE and other models can be added to a well-understood macro model to see whether they aid in the explanation of macroeconomic developments and forecasting. Second, different measures can be used to see which type of proxy is most helpful in capturing the linkages. Third, the small size of the model allows for experimentation of various types. For example, should a proxy for financial-real linkages be introduced as simply an extra variable in the model that functions continuously or should it only be allowed to affect behavior when it reaches critical threshold levels of the sort that were seen in the episodes in which financial-real linkages played a central role? Fourth, by allowing for persistence in real and financial shocks and in their effects on the real economy, judgmental near-term forecasts of these shocks can play an important role in model-based, medium-term projections through the setting of initial conditions. Fifth, multi-country models with financial-real linkages will allow us to see whether cross-border financial effects have played an important role in transmitting the business cycle internationally, and to assess the relative importance of real linkages and financial linkages in transmitting shocks across countries. $^{14}$

In this paper, we use only one financial variable (over and above interest rates and exchange

\footnotetext{
${ }^{13}$ See Lown, Morgan, and Rohatgi (2000), Lown and Morgan (2002), Lown and Morgan (2006), Swiston (2008), and Bayoumi and Melander (2008) for earlier attempts to assess the effects of financial-real linkages.

${ }^{14}$ Bayoumi and Swiston (2007) use VARs to try to achieve the same objective.
} 
rates), the bank lending tightening variable for the United States $\left(\mathrm{BLT}_{U S}\right)$. In future papers, we plan to examine the potential role of BLT variables in other countries and a variety of spread measures, such as bond spreads, swap spreads, and credit default swap spreads.

\section{B. Model Specification Incorporating the US Bank Lending Tightening Variable}

The financial variable $\mathrm{BLT}_{U S}$ is an unweighted average of the responses to four questions with respect to tightening terms and conditions in the Federal Reserve Board's quarterly Senior Loan Officer Opinion Survey on Bank Lending Practices. More precisely, for each of four questions on bank credit standards on loan applications, ${ }^{15}$ net tightening is equal to the sum of the percentage of banks responding "tightened considerably" and "tightened somewhat" less the sum of the percentage of banks responding "eased somewhat" and "eased considerably". These net tightening variables are each weighted by one quarter to give the overall BLT variable. It is worth noting that the net tightening responses from the survey outweigh the net easing responses on average over the sample period, indicating a bias of about $5 \%$ in the variable.

The model with financial-real linkages makes two substantive changes to the benchmark model set out earlier. In equation $18, \mathrm{BLT}_{U S}$ is a function of $\overline{B L T}_{U S}$, the equilibrium level of $\mathrm{BLT}_{U S}$, which itself is a random walk (equation 19), and a disturbance term, $\varepsilon_{U S}^{B L T}{ }^{16}$

$$
\begin{gathered}
B L T_{U S, t}=\overline{B L T}_{U S, t}-\kappa_{U S} y_{U S, t+4}-\varepsilon_{U S, t}^{B L T} \\
\overline{B L T}_{U S}=\overline{B L T}_{U S, t-1}+\varepsilon_{U S, t}^{\overline{B L T}}
\end{gathered}
$$

As shown in equation 18, banks are assumed to tighten or ease their lending practices in part depending on their view of the expected behavior of the economy 4 quarters ahead. That is, if the output gap is assumed to be positive (a strong economy), there will be a tendency to ease

\footnotetext{
${ }^{15}$ Question 1a on C\&I loans or credit lines to large and middle-market firms, question 1b on C\&I loans or credit lines to small firms, question 8 on commercial real estate loans, and question 10 on mortgage loans to purchase homes.

${ }^{16}$ In the earlier papers the disturbance term was entered with a negative sign to simplify the US cross correlations, and the same specification has been maintained for this paper.
} 
lending conditions, while if it is assumed to be negative (a weak economy), there will be a tendency to tighten lending conditions.

In equation 20, the output gap is explained by the same variables as in the US version of equation 13 (a lead and lag of the output gap, the real interest rate gap, the foreign activity gap and the effective exchange rate gap), as well as by $\eta_{U S}$, a distributed lag of $\varepsilon_{U S}^{B L T}$. Thus, if lending conditions are easier than might have been anticipated on the basis of expectations of future economic behavior (positive $\varepsilon_{U S}^{B L T}$ ), the effect will be a larger output gap and a sronger economy.

$$
\begin{aligned}
y_{U S, t}= & \beta_{U S, 1} y_{U S, t-1}+\beta_{U S, 2} y_{U S, t+1}-\beta_{U S, 3} r_{U S, t-1}+\beta_{U S, 4} \sum_{j} \omega_{U S, 4, j} \\
& \left(-z_{j, U S, t-1}\right)+\beta_{U S, 5} \sum_{j} \omega_{U S, j, 5} y_{j, t-1}+\theta_{U S} \eta_{U S, t}+\varepsilon_{U S, t}^{y} \\
\eta_{U S, t}= & 0.04 \varepsilon_{U S . t-1}^{B L T}+0.08 \varepsilon_{U S, t-2}^{B L T}+0.12 \varepsilon_{U S, t-3}^{B L T}+0.16 \varepsilon_{U S, t-4}^{B L T}+0.20 \varepsilon_{U S, t-5}^{B L T} \\
+ & 0.16 \varepsilon_{U S, t-6}^{B L T}+0.12 \varepsilon_{U S, t-7}^{B L T}+0.08 \varepsilon_{U S, t-8}^{B L T}+0.04 \varepsilon_{U S, t-9}^{B L T}
\end{aligned}
$$

The values of the coefficients imposed in equation 21 are intended to reflect a pattern in which an increase of $\varepsilon_{U S}^{B L T}$ (an easing of the bank lending conditions variable) is expected to positively affect spending by firms and households in a hump-shaped fashion, with an initial buildup and then a gradual rundown of the effects.

There are at least two ways of thinking about the way that the $\varepsilon_{U S}^{B L T}$ variable functions in the model. In the first, this proxy variable for financial tightening can be thought of as capturing the exogenous element in bank lending that has the potential to set in motion a weakening or strengthening economic situation. That is, those responsible for bank lending look forward to economic conditions about a year in the future and tighten or loosen in part on the basis of their expectations. If their actions are typical for the stage of the cycle, the interest rate variable itself may pick up the normal tightening and easing of terms and conditions on bank lending, and BLT would play little role in driving future economic developments. If, on the other hand, their actions are greater or less than is typical in light of the expected economic situation, this could have a direct effect on the ability of borrowers to access funds and to make expenditures. A second interpretation puts less emphasis on the direct effects on expenditures of the tightening or easing of bank lending conditions. Rather, from this 
perspective, one can consider the $\varepsilon_{U S}^{B L T}$ variable as reflecting the views of experts on the lending side of the economy with respect to future economic and financial conditions and thereby functioning as a very useful leading indicator of economic developments.

There are a number of issues surrounding this variable. First, in the interpretation that focuses on the exogenous part of this variable, it is assumed that the part of financial-real linkages that propagates other typical shocks to the system is captured by the interest rate. This is not an unreasonable assumption, since the endogenous part of the financial accelerator mechanism intensifies the effects on the economy of other shocks and, in a macro sense, could be thought of as simply increasing the coefficient on the interest rate variable. Second, there could be an asymmetry between tightening and easing shocks to $\mathrm{BLT}_{U S}$. While financial conditions that are tighter than typical will have the effect of preventing liquidity-constrained households and businesses from achieving their desired expenditures, beyond a certain point the easing of financial conditions may be less powerful in leading to increased spending. That is, once there is sufficient collateral to satisfy lenders of the safety of their loans, a further increase in the value of the collateral may not affect their behavior very much. ${ }^{17}$ Third, it is possible that small changes in financial conditions will have relatively minor effects, and only changes beyond a certain critical threshold will have the capacity to bring about economically significant changes. Fourth, given the complexity of the financial-real linkages in the economy, $\mathrm{BLT}_{U S}$ may not be able to capture all of these types of linkages, and other variables (such as risk spreads) will be introduced into the output gap equations in future papers to try to pick up some of the other effects.

\section{Confronting the Model with the Data}

\section{A. Bayesian Estimation}

Bayesian estimation provides a middle ground between classical estimation and the calibration of macro models. The use of classical estimation in a situation of a relatively small sample size (which is almost always the case for time series data) often gives model results that are strange, and are inconsistent with the views of macroeconomists as to the functioning

\footnotetext{
${ }^{17}$ It could, however, affect borrower behavior.
} 
of the economy. This problem is accentuated by the simultaneity challenges to macro models, which are not handled well by simultaneous equation methods in small samples. For example, because an aggregate demand shock can lead to persistent inflationary pressures and to central bank actions to raise interest rates to offset the shock, classically estimated models using time series data will sometimes show an increase in interest rates leading to an increase in inflation. This is particularly problematic when the model is to be used for policy simulations, since it may well indicate the need for an interest rate decline to slow the rate of inflation.

Models with calibrated parameters avoid this problem, but are often criticized as representing no more than the modelers' judgment, which may or may not be consistent with the data. While calibration is typically based on the understanding of experts of the functioning of the economy, the desire to confront the model with the data in a statistical sense has led researchers to use Bayesian estimation techniques to estimate models.

The Bayesian approach has the benefit of putting some weight on the priors of the researchers and some weight on the data over the sample period. By changing the specification of the tightness (e.g., the standard deviation) of the distribution on the priors, the researcher can change the relative weights on the priors and the data in determining the posterior distribution for the parameters. In the limit, a diffuse or noninformative distribution puts more weight on the data while a distribution with a very tight prior distribution (e.g., a small standard deviation) puts more weight on the priors.

There are a number of criteria by which researchers evaluate the success of Bayesian estimated models and decide between models with different weights placed on priors and the data. First, if an estimated model yields coefficients that are close to the priors in spite of allowing considerable weight to be placed on the data, this indicates that the priors are not inconsistent with the data. A second criterion involves seeing whether the impulse response functions (IRFs) from the model estimated with Bayesian techniques are compatible with the views of the researchers (and in the case of models built at central banks with the views of the management of the central bank) with respect to the functioning of the economy in response to shocks. Third, in comparing different variants of a given macro model (for example, one that treats shocks to output as largely demand determined and another that treats shocks as largely supply determined), researchers can use the relative magnitudes of the log data density and root mean squared errors (RMSEs) as indications of which model is more consistent with the data. And, fourth, the plausibility of the variance decomposition of the variables in the 
model can help to indicate whether the model is sensible. ${ }^{18}$

Bayesian estimated models are likely to have better model properties than classically estimated models, but may sometimes not fit the data as well as simple VAR models, since the sole purpose of the latter is to maximize fit. It is the combination of reasonable fit, appropriate structural results from a theoretical perspective, and the ability to give sensible results for policy simulations that gives estimated Bayesian models their strength. Also, the use of such models along with judgmental inputs for the first two quarters of the forecast period is likely to give better and more sensible forecasting results than most other models. A comparison of Bayesian-estimated Global Projection Models with competitor global models will be presented in one of the future papers in this series.

\section{B. Results}

\section{B.1 Estimates of output gap}

The estimates on the model consistent output gap presented in Figure 1 show that in 2003-04, the LA5 economies were operating well below potential, helping curb inflation. With the increase in aggregate demand following favorable terms of trade shocks, this gap had closed by late 2006 and, towards the end of the sample, these countries were operating close to or above potential.

\section{B.2 Estimates of coefficients}

The estimates for the coefficients for the three large economies and for their standard deviation of structural shocks and cross correlations can be found in tables 1 through 5 of Carabenciov and others (2008b). In this section we present the estimation results for LA5, the aggregate of five Latin American economies (Brazil, Chile, Colombia, Mexico and Peru) when it is added to the earlier three country model. The common element in the countries included in LA5 during this period is the choice of inflation targeting as their monetary policy

\footnotetext{
${ }^{18}$ For example, in a two country model, if the variance decomposition showed that a shock to the output gap equation of the large country had a smaller effect on the output gap of the small country than the reverse, considerable doubt would be thrown on the validity or usefulness of the model results.
} 
framework. Recall that for purposes of this exercise the coefficients on the equations of the three large economies - US, euro area and Japan — are frozen at their values in the earlier three country model and are not affected by the addition of LA5 to the model. Note also that in estimating the LA5 parameters, we take as observable variables the estimated latent variables for the United States, the euro area and Japan, and presented in Carabenciov and others (2008b). ${ }^{19}$ That is, for estimation purposes (but not for simulation purposes), it is assumed that the introduction of the new economy to the model would have little effect on the coefficients of the large countries.

The model that includes the Latin American aggregate economy, LA5, is estimated over the sample period 2001Q4 to 2008Q2. Table 1 sets out estimation results for the parameters for LA5 in this version of the model, showing the distribution used in the estimation, the prior mean, the prior standard deviation, the posterior mode, and the posterior standard deviation. Figures 2 through 4 present some of the key parameter estimates for LA5, the five component economies of LA5, and the three large economies. ${ }^{20}$

We begin with the output gap equations (table 1 and figure 2). Like the three large economies, LA5 has appreciably more weight on the backward-looking component, $\beta_{1}$, than on the forward-looking component, $\beta_{2}$. However, LA5 and its constituent economies tend to have considerably less weight on the backward-looking component and more weight on the forward-looking component than do the three large economies. The smaller backward looking component, by itself, would suggest that the output gap would have less inertia in LA5 than in the large economies and, if other parameters were the same, that demand shocks would have less persistent effects. However, when shocks to the output gap, i.e., demand shocks, are allowed to work through the dynamics of the model, which operate through both backward and forward looking components and through several channels, the impulse response functions for LA5 and the advanced economies are very similar. Also, the sum of the coefficients on the backward-looking component and the forward-looking component in LA5 is considerably lower than in the euro area and Japanese economies. The LA5 coefficients on the real interest rate gap, $\beta_{3}$, and on the real exchange rate gap, $\beta_{4}$, are similar to those in the

\footnotetext{
${ }^{19}$ In particular, the values of the output gap $\left(y_{i}\right)$ and the real exchange rate gap $\left(z_{i}\right)$ for the euro area and Japan estimated by Carabenciov and others (2008b) are used in the estimation of the LA5 parameters.

${ }^{20}$ More detailed results for the five component economies are available upon request from rgarciasaltos@imf.org or jcanaleskriljenko@imf.org.
} 
three large economies. In contrast, the coefficient on the activity variable, $\beta_{5}$, is five to ten times larger in LA5 than in the large economies, in line with the greater openness of the Latin American economies.

Inflation in LA5 has become increasingly linked to expected future inflation as opposed to past inflation. In particular, the proportion of inflation explained by forward-looking variables has increased over time. The estimate of $\lambda_{1}$ in the inflation equation (table 1 and figure 3 ) also indicates that inflation in these five countries is considerably less forward looking than in the United States, the Euro area, and Japan. This would suggest that the Latin American economies would have more difficulty disinflating from an initial high level of inflation than the large global economies. The effect of the output gap on inflation in LA5, $\lambda_{2}$, is somewhat larger than in the three economies. And the effect of exchange rate changes on inflation, $\lambda_{3}$, is much larger than that in the three large economies, consistent with the literature on pass-through from the exchange rate movements to inflation in emerging economies. ${ }^{21}$ This result is also consistent with the concern in emerging economies about exchange rate movements, even under an inflation targeting regime.

In the interest rate reaction functions (table 1 and figure 4), the smoothing coefficient, $\gamma_{1}$, in LA5 is a little smaller than that in the three large economies. The response to deviations of inflation from target, $\gamma_{2}$, is about the same in LA5 as that for the euro area and higher than that for Japan and the United States. ${ }^{22}$ The coefficients on the LA5 output gap, $\gamma_{4}$, is about the same as in the other economies.

There are a number of other results of interest. The estimated target inflation rate for LA5 is about $4.2 \%$ and the estimated equilibrium real interest rate is $4.8 \%$, both considerably higher than their respective priors and those observed in advanced economies. The steady-state growth rate for LA5 is $3.7 \%$, lower than the prior of $4 \%$. In LA5, as in the three large economies, the response of the unemployment gap to the output gap, or the Okun coefficient, $\alpha_{2}$, is considerably smaller than anticipated. In LA5, the persistence of growth in the NAIRU to shocks, $\left(1-\alpha_{3}\right)$, is somewhat smaller than anticipated, the reverse of the result in the other economies. In contrast, the persistence of growth in potential output in LA5 to shocks, $(1-\tau)$

\footnotetext{
${ }^{21}$ See, for example, Frankel, Parsley and Wei (2005).

${ }^{22}$ Note, however, that because of the specification of the equation, the response of interest rates to an increase in forecast inflation, $\pi 4_{i, t+3}$, is $\gamma_{2}$ plus 1 . The stability requirement that the response of the rate of interest to an increase in the rate of inflation must exceed unity is easily met in all the economies.
} 
is somewhat higher than anticipated, consistent with the result in the three large economies. The persistence of the equilibrium real interest rate to shocks, $(1-\rho)$, is much higher in LA5 than in the three large economies. Finally, the expected real exchange rate in LA5 is very forward looking, as shown by the estimate of $\phi$, although somewhat less than is the case for the euro and the yen.

\section{B.3 Estimates of standard deviation of structural shocks and cross correlations}

Table 2 presents the same information for the standard deviations of the structural shocks in LA5 as was shown in table 1 for the coefficient estimates, making use of more diffuse priors. Given that the priors for the estimates of the standard deviation of the structural shocks are held with much less confidence than the priors for the coefficients, it is not surprising that the posterior results tend to differ more from the priors than was the case for the coefficients. Particularly worth noting are the much higher posteriors than expected for the standard deviations of the shocks to the equilibrium real exchange rate, the rate of inflation, and the unemployment rate gap. There were also a number of much lower than expected posteriors for the standard deviations of shocks, including the shocks to the output gap, UIP, NAIRU, and NAIRU growth. These results indicate that, compared to prior expectations, there is considerably less uncertainty about the shock terms pertaining to unemployment and UIP, and considerably more about the shock terms pertaining to real exchange rates and inflation.

As shown in table 3 , the posterior results for the cross correlations are generally in line with their priors and very similar to the estimates of cross correlations in the large countries.

\section{B.4 RMSEs}

The RMSEs for the United States, the euro area, and Japan, which are based on the intra-sample forecasts without any judgmental input, can be found in Table 6 of Carabenciov and others (2008b). Table 4 presents the corresponding RMSEs for the LA5 equations. With the exception of the unemployment rate, the RMSEs for LA5 are significantly higher than those for the euro area. On balance, however, they tend to be lower for the output and unemployment variables than in the US and Japanese economies, but higher for the inflation and interest rate variables. 


\section{B.5 Impulse response functions}

The impulse response functions for demand and financial shocks in the three large economies can be found in figures 2 through 13 of Carabenciov and others, 2008b. Figures 5 through 8 present a selection of the LA5 model's most important impulse response functions, which show reasonable and expected patterns. ${ }^{23}$

Figure 5 shows the effects on LA5 of a domestic demand shock. An increase in domestic demand causes inflationary pressures, which trigger a monetary policy reaction that raises the interest rate. In turn, the higher interest rate results in downward pressure on spending by residents and in an appreciation of the real exchange rate (via UIP), which decreases the net export component of aggregate demand. The typical demand shock in LA5 is somewhat smaller than that in the three large economies. When account is taken of the somewhat smaller shock, most of the effects of the domestic demand shock in LA5 are qualitatively and quantitatively similar to the domestic effects of demand shocks in the large economies.

Figures 6,7 and 8 show the effects on the LA5 economy of domestic price shocks, a demand shock in the United States, and a financial (BLT) shock in the United States. The domestic price shock in LA5 (figure 6) has qualitatively similar results to the effect of a US price shock on the US economy. However, even taking into account the different sizes of the typical price shocks, the effect of the LA5 price shocks on the LA5 output gap, interest rates and unemployment rates are considerably larger than the corresponding US shock on the US economy. A demand shock in the United States (figure 7) has on the order of 50\% larger effect on LA5 output, inflation and domestic interest rates than it has on the corresponding euro area variables, which is consistent with the larger role played by the US economy vis-à-vis LA5 than vis-à-vis the Euro area. And the BLT shock in the United States (figure 8) also has a somewhat larger effect on LA5 output, inflation and domestic interest rates than it does on the corresponding euro area variables. This is consistent with the fact that BLT has its effects on the US economy through its influence on its output gap and the greater role of the US economy in LA5 than in the euro area. An interesting finding is that US BLT shocks affect Latin America with a lag - a peak effect occurs after two years - and are more persistent than U.S. demand shocks. These effects are a result of the distributed lag effects of BLT shocks in

\footnotetext{
${ }^{23}$ The impulse responses are computed using a Cholesky decomposition of the covariance matrix of the exogenous shocks using the same ordering as in Carabenciov and others (2008b).
} 
the US output gap equation.

\section{B.6 Historical variance decomposition}

Figure 9 presents a decomposition of LA5 inflation for the period 2004Q1 to 2008Q2 in terms of the deviation in percentage points from the estimated inflation target of $4.2 \%$. The interpretation of history embedded in the GPM estimates suggests that cost-push factors, identified as shocks to the inflation equation, have played a crucial role. These shocks have arisen from large movements in commodity prices, which affected Latin American consumer prices. At the same time, currency appreciation in Latin America has helped offset inflationary pressures. Note that LA5 economies are net commodity exporters and thus commodity price shocks translated into appreciations of the LA5 currencies and positive net income effects. Idiosyncratic monetary policy shocks, that is higher interest rate increases than those called for by the estimated Taylor rule, played a role in lowering inflation in 2006, and had a protracted but waning effect later in the period. The other more than 40 shocks, including shocks to the output gap in LA5 and other countries in the model, do not appear to have played an important role as a whole in explaining deviations of inflation from the estimated target rate.

\section{Concluding Remarks}

This is the fourth of a series of papers that are being written as part of a larger project to estimate a small quarterly Global Projection Model (GPM). The GPM project is designed to improve the toolkit to which economists have access for studying both own-country and cross-country macro linkages and financial-real linkages. In this paper, we added a fourth country (an aggregate of the five inflation-targeting Latin American economies) to the small quarterly projection model of three large economies (United States, euro area, and Japan) in which the key variables were output gaps, unemployment gaps, inflation rates, short-term interest rates, and exchange rates. We also included a financial variable (in the form of a US bank lending tightening variable) into the model to allow for financial-real linkages. The model was estimated with Bayesian techniques, which provide a very efficient way of imposing restrictions to produce both plausible dynamics and sensible forecasting properties. 
An important advantage of these techniques is that they allow researchers to estimate models with flexible stochastic processes, which can provide timely and more efficient model-consistent measures of potential output and other latent variables in the system. After presenting the posterior estimates, impulse response functions, and RMSEs for intra-sample forecasts, we showed how the model can be used to construct a variance decomposition of the recent history of inflation in LA5.

The next phases of the project will be to develop a more sophisticated model of the oil market, to expand the model to include financial variables in other countries, and to build a global version of the model (with several countries and a residual economy) and use it to assess whether spillovers across countries are generated more through financial linkages than through conventional trade linkages. It can also be used to compare forecasting results with those of competitor models of the global economy. 


\section{References}

Argov, E., N. Epstein, P. Karam, D. Laxton, and D. Rose, 2007, "Endogenous Monetary Policy Credibility in a Small Macro Model of Israel," IMF Working Paper 07/207 (August), available at www.imf.org.

Bayoumi, T. and A. Swiston, 2007, "Foreign Entanglements: Estimating the Source and Size of Spillovers Across Industrial Countries," IMF Working Paper No. 07/182 (July), available at www.imf.org.

Bayoumi, T. and O. Melander, 2008, “Credit Matters: Empirical Evidence on U.S. Macro-Financial Linkages,” IMF Working Paper No. 08/169 (July), available at www.imf.org.

Berg, A., P. Karam, and D. Laxton, 2006a, "A Practical Model-Based Approach to Monetary Policy Analysis - Overview,” IMF Working Paper 06/080 (April), available at www.imf.org.

Berg, A., P. Karam, and D. Laxton, 2006b, "Practical Model-Based Monetary Policy Analysis-A How-to Guide,” IMF Working Paper 06/081 (April), available at www.imf.org.

Bernanke, B. S. and M. Gertler, 1995, "Inside the Black Box: The Credit Channel of Monetary Policy Transmission," Journal of Economic Perspectives (Fall), pp. 27-48.

Botman, D., P. Karam, D. Laxton, and D. Rose, 2007, "DSGE Modeling at the Fund: Applications and Further Developments," IMF Working Paper 07/200 (August), available at www.imf.org.

Carabenciov, I., I. Ermolaev, C. Freedman, M. Juillard, O. Kamenik, D. Korshunov and D. Laxton, 2008a, “A Small Quarterly Projection Model of the US Economy,'IMF Working Paper No. 08/278, available at www.imf.org.

Carabenciov, I., I. Ermolaev, C. Freedman, M. Juillard, O. Kamenik, D. Korshunov, D. Laxton, and J. Laxton, 2008b, “A Small Quarterly Multi-Country Projection Model," IMF Working Paper No. 08/279, available at www.imf.org. 
— 2008c, "A Small Quarterly Multi-Country Projection Model with Financial-Real Linkages and Oil Prices," IMF Working Paper No. 08/280, available at www.imf.org.

Coats, W., D. Laxton and D. Rose, 2003, The Czech National Bank's Forecasting and Policy Analysis System. Prague, Czech Republic: Czech National Bank.

Dornbusch, R., 1976, "Expectations and Exchange Rate Dynamics," Journal of Political Economy, December, 1161-76.

Epstein, N., D. Laxton. P. Karam and D. Rose, 2006, "A Simple Forecasting and Policy Analysis System for Israel: Structure and Applications" in Israel: Selected Issues, IMF Country Report No. 06/121 (March), available at www.imf.org.

Frankel, J. A., D. C. Parsley and S.-J. Wei, 2005, "Slow Passthrough Around the World: A New Import for Developing Countries?” NBER Working Paper No. 11199.

Juillard, M., O. Kamenik, M. Kumhof, and D. Laxton, 2007, "Measures of Potential Output from an Estimated DSGE Model of the United States" paper presented at a workshop on Issues in Measuring Potential Output, Ankara Turkey, January 16, 2007.

- 2008, "Optimal Price Setting and Inflation Inertia in a Rational Expectations Model," Journal of Economic Dynamics and Control, volume 32, issue 8, pp. 2584-2621.

Laidler D., 2003, "The price level, relative prices and economic stability: aspects of the interwar debate," BIS Working Papers No. 136 (September), available at www.bis.org.

Lown, C., D. Morgan, and S. Rohatgi, 2000, "Listening to Loan Officers: The Impact of Commercial Credit Standards on Lending and Output," Federal Reserve Bank of New York Economic Policy Review (July), pp. 1-16.

Lown, C. and D. Morgan, 2002, "Credit Effects in the Monetary Mechanism," Federal Reserve Bank of New York Economic Policy Review (May), pp. 217-35.

_ 2006, "The Credit Cycle and the Business Cycle: New Findings Using the Loan Officer Opinion Survey,” Journal of Money, Credit, and Banking, Vol. 38 (September), pp. 1575-97. 
Orphanides, A., 2003, "Historical monetary policy analysis and the Taylor rule," Journal of Monetary Economics (July), pp. 983-1022.

Swiston, A., 2008, “A U.S. Financial Conditions Index: Putting Credit Where Credit is Due," IMF Working Paper No. 08/161 (June), available at www.imf.org. 
Appendix: GPM Data Definitions

United States

GDP U.S.: $\quad$ Gross Domestic Product (SAAR, Bil.Chn.2000.Dollars)

Interest rates $\quad$ Federal Open Market Committee: Fed Funds Target Rate (percent) (period average)

CPI U.S.: $\quad$ Consumer Price Index (SA, 1982-84=100)

Core CPI U.S.: CPI-U: All Items Less Food and Energy (SA, 1982-84=100)

Unemployment U.S.: Civilian Unemployment Rate (SA, percent)

Bank lending

tightening (BLT) Average of:

FRB Sr Officers Survey: Banks Tightening C.I Loans to Large Firms (percent)

FRB Sr Officers Survey: Banks Tightening C.I Loans to Small Firms (percent)

FRB Sr Loan Off Survey: Tightening Standards for Commercial Real Estate (percent)

FRB Sr Loan Survey: Res Mortgages: Net Share, Banks Tightening (Haver Est, percent)

Euro Area

\begin{tabular}{ll}
\hline \hline GDP Euro & Area15: Gross Domestic Product (SA/WDA, Mil.Chn.00.Euros) \\
Interest rates & Euro Area11-15: 3-Month EURIBOR Rate (AVG, percent) \\
CPI Euro & Area15: Monetary Union Index of Consumer Prices (SA, 2005=100) \\
Core CPI & Euro Area15: MUICP: Total excl Energy, Food, Alcohol and Tobacco(SA, 2005=100) \\
Unemployment & Euro Area15: Unemployment Rate (SA,percent) \\
Exchange Rates & Period averages; increase is depreciation
\end{tabular}

Japan

GDP Japan: $\quad$ Gross Domestic Product (SAAR, Bil.Chn.2000.Yen)

Interest rates Japan: Call Rate: Uncollateralized 3-Month (EOP, percent)

CPI Japan: $\quad$ Consumer Price Index (SA, 2005=100)

Core CPI Japan: CPI: All Items excluding Food and Energy (SA, 2005=100)

Unemployment Japan: Unemployment Rate (SA, percent)

Exchange Rates Period averages; increase is depreciation

Brazil

GDP Brazil: $\quad$ Gross Domestic Product, Chained Index (SA, 1995=100)

Interest rates Brazil: Overnight Rate: Overnight Rate: Over/Selic (AVG, percent)

CPI Brazil: $\quad$ Consumer Price Index (SA, 2005=100)

Unemployment Brazil: Unemployment Rate, all metropolitan regions (SA, percent)

Exchange Rates Period averages; increase is depreciation 
Appendix: GPM Data Definitions (continuation)

Chile

GDP Chile

Interest rates

CPI Chile

Unemployment

Exchange Rates

Colombia

GDP Colombia
Interest rates

CPI Colombia

Unemployment

Exchange Rates

Mexico

GDP Mexico

Interest rates

CPI Mexico

Unemployment

Exchange Rates

Peru

GDP Peru:

Interest rates

CPI Peru:

Unemployment

Exchange Rates
Gross Domestic Product (SA, Mil.2003.Ch Pesos)

Chile: Monetary Policy Rate (EOP, percent)

Consumer Price Index, quarterly average (SA, Dec 1998=100)

Chile: Unemployment Rate: Quarterly moving average (SA, percent)

Period averages; increase is depreciation

Colombia: Lending Interbank Rate (AVG, Percent)

Consumer Price Index, quarterly average (SA, Dec. 1998=100)

Colombia: Unemployment Rate (SA, percent)

Period averages; increase is depreciation

Gross Domestic Product (SAAR, Mil.1993 NewPesos)

Mexico: 3-month Treasury Bill (AVG, percent)

Consumer Price Index (SA, Jun 16-30, 2002=100)

Mexico: Unemployment Rate (SA, percent)

Period averages; increase is depreciation

LA5 Aggregate

Aggregation used PPP-based GDP weights.

Weights applied to quarterly changes in GDP growth, CPI,

real exchange rate, levels of unemployment and of interest rates.

Real Effective Weighted averages of the bilateral exchange rates.

Exchange Rates

Weights are based on bilateral trade data from IMF Direction of Trade database (2006).

The rates in the inflation equations are defined with import weights, while the rates in the output gap equations use total trade (imports+exports) weights.

Foreign Outp. Gaps Weighted averages of the lagged foreign output gaps. Weights are based on bilateral trade data (exports) from IMF Direction of Trade db (2006). 
Appendix: Trade Matrix (Average 2001-2007, in percent)

\begin{tabular}{l|l|llll}
\hline \hline \multicolumn{2}{l|}{} & LA5 & US & EU & Japan \\
\hline Exports Destination & LA5 & - & 79 & 18 & 4 \\
& US & 37 & - & 48 & 15 \\
& Euro Area & 12 & 75 & - & 13 \\
& Japan & 5 & 59 & 37 & - \\
\hline Inport Origin & LA5 & - & 69 & 23 & 8 \\
& US & 32 & - & 46 & 22 \\
& Euro Area & 14 & 59 & - & 26 \\
& Japan & 9 & 51 & 41 & - \\
\hline Trade & LA5 & - & 74 & 20 & 5 \\
(Exports plus Imports) & US & 32 & - & 46 & 22 \\
& Euro Area & 14 & 59 & - & 26 \\
& Japan & 9 & 51 & 41 & - \\
\hline \hline Source
\end{tabular}

Source: Direction of Trade Statistics 
Figure 1: Output Gap in LA5

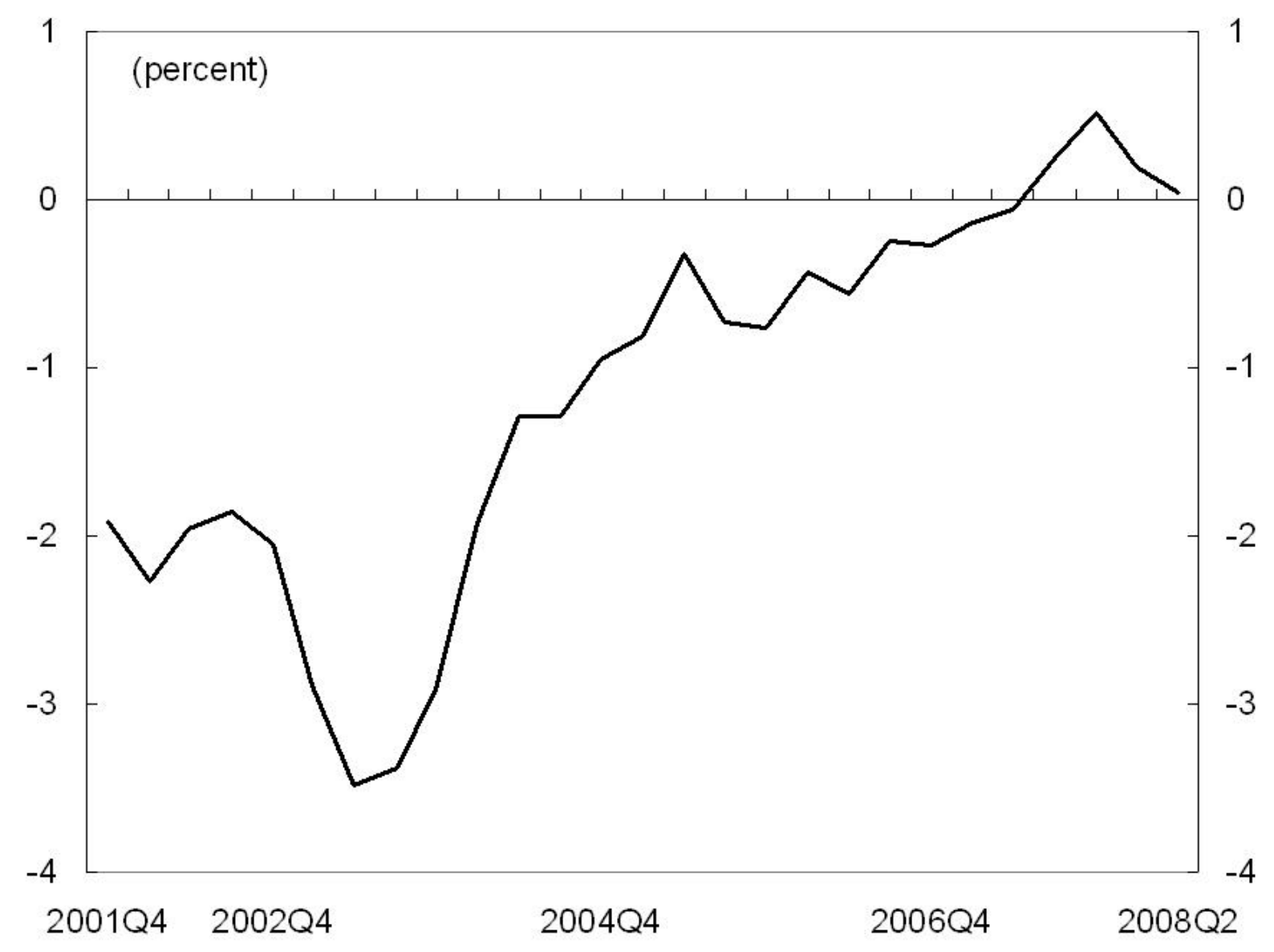


Table 1: Results from Posterior Maximization

\begin{tabular}{l|lcccc}
\hline \hline & Prior distribution & Prior mean & Prior s.d. & Posterior mode & s.d. \\
\hline$\alpha_{l a 5,1}$ & beta & 0.750 & 0.1000 & 0.6711 & 0.0845 \\
$\alpha_{l a 5,2}$ & gamm & 0.300 & 0.1000 & 0.2331 & 0.0565 \\
$\alpha_{l a 5,3}$ & beta & 0.500 & 0.2000 & 0.5446 & 0.2564 \\
$\beta_{l a 5,1}$ & gamm & 0.600 & 0.1000 & 0.4875 & 0.0655 \\
$\beta_{l a 5,2}$ & beta & 0.200 & 0.0500 & 0.1796 & 0.0455 \\
$\beta_{l a 5,3}$ & gamm & 0.200 & 0.0500 & 0.1622 & 0.0399 \\
$\beta_{l a 5,4}$ & gamm & 0.050 & 0.0040 & 0.0499 & 0.0040 \\
$\beta_{l a 5,5}$ & gamm & 0.250 & 0.1000 & 0.1886 & 0.0736 \\
$\gamma_{l a 5,1}$ & beta & 0.500 & 0.0500 & 0.6216 & 0.0398 \\
$\gamma_{l a 5,2}$ & gamm & 1.500 & 0.2000 & 1.2244 & 0.1680 \\
$\gamma_{l a 5,4}$ & gamm & 0.200 & 0.0500 & 0.1877 & 0.0488 \\
$\pi_{\text {la5 }}^{t a r}$ & gamm & 3.000 & 0.5000 & 4.2185 & 0.6995 \\
$g_{\text {las }}$ & norm & 4.000 & 1.0000 & 3.6824 & 0.3073 \\
$\lambda_{\text {la5,1 }}$ & beta & 0.500 & 0.1000 & 0.5730 & 0.0703 \\
$\lambda_{\text {la5, }}$ & gamm & 0.250 & 0.0500 & 0.2331 & 0.0476 \\
$\lambda_{l a 5,3}$ & gamm & 0.150 & 0.0500 & 0.1488 & 0.0482 \\
$\phi_{l a 5}$ & beta & 0.500 & 0.2000 & 0.7923 & 0.0704 \\
$\rho_{l a 5}$ & beta & 0.300 & 0.1000 & 0.1539 & 0.0688 \\
$\overline{r r}_{l a 5}$ & norm & 4.000 & 0.5000 & 4.7678 & 0.5233 \\
$\tau_{l a 5}$ & beta & 0.075 & 0.0300 & 0.0643 & 0.0279 \\
\hline \hline
\end{tabular}


Figure 2: Estimated Parameters in the Output Gap Equation
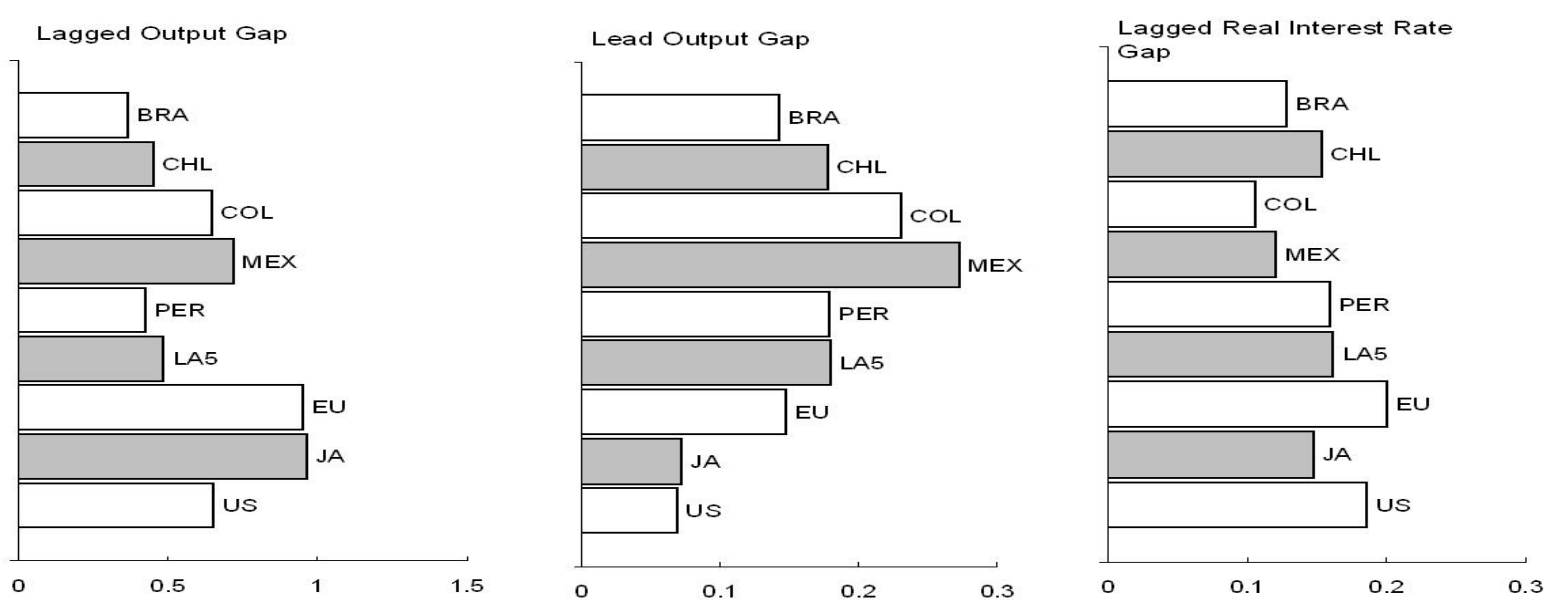

Lagged Foreign Output Gap

Lagged Real Exchange Rate Gap
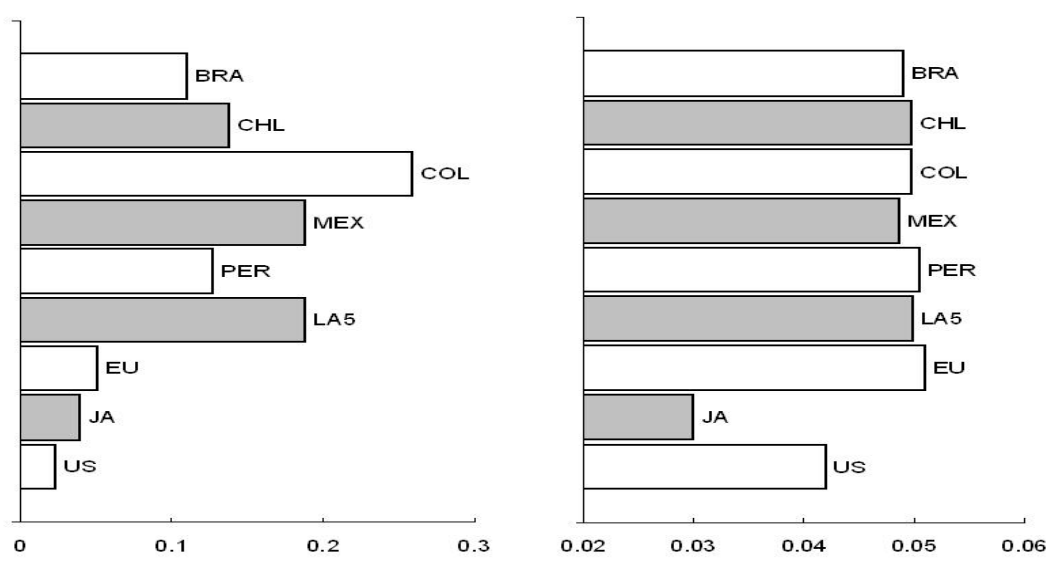
Figure 3: Estimated Parameters in the Inflation Equation
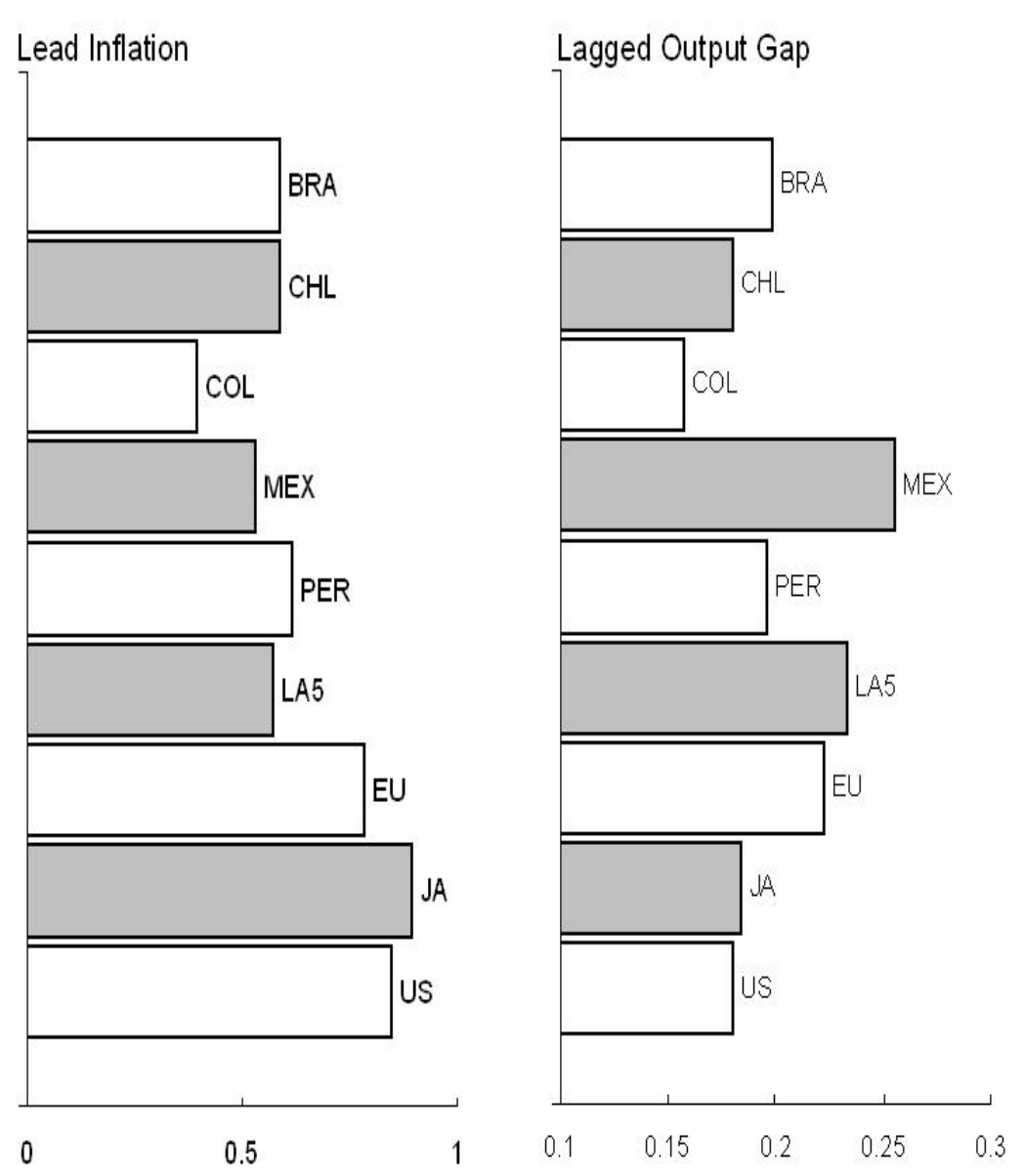

Change in Effective Exchange

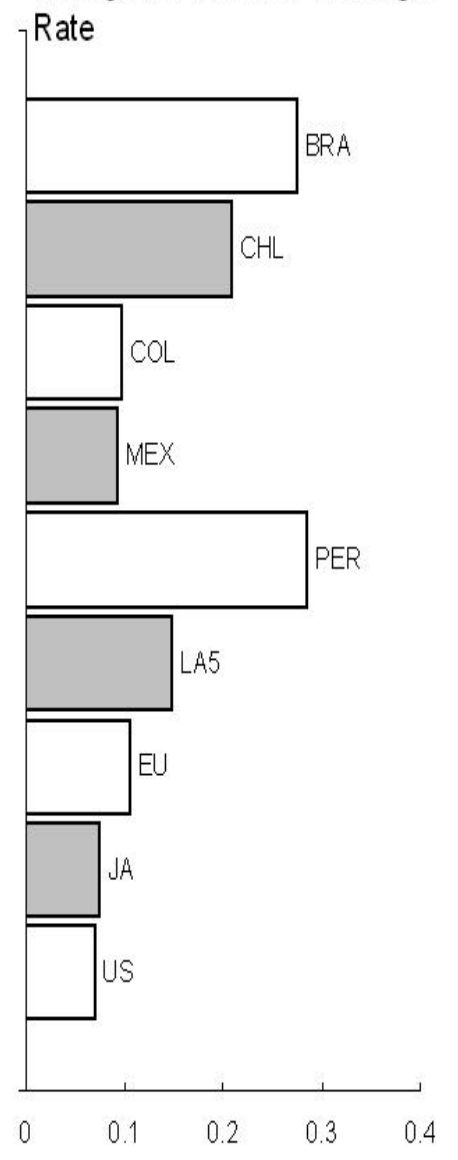


Figure 4: Estimated Parameters in the Monetary Policy Rule
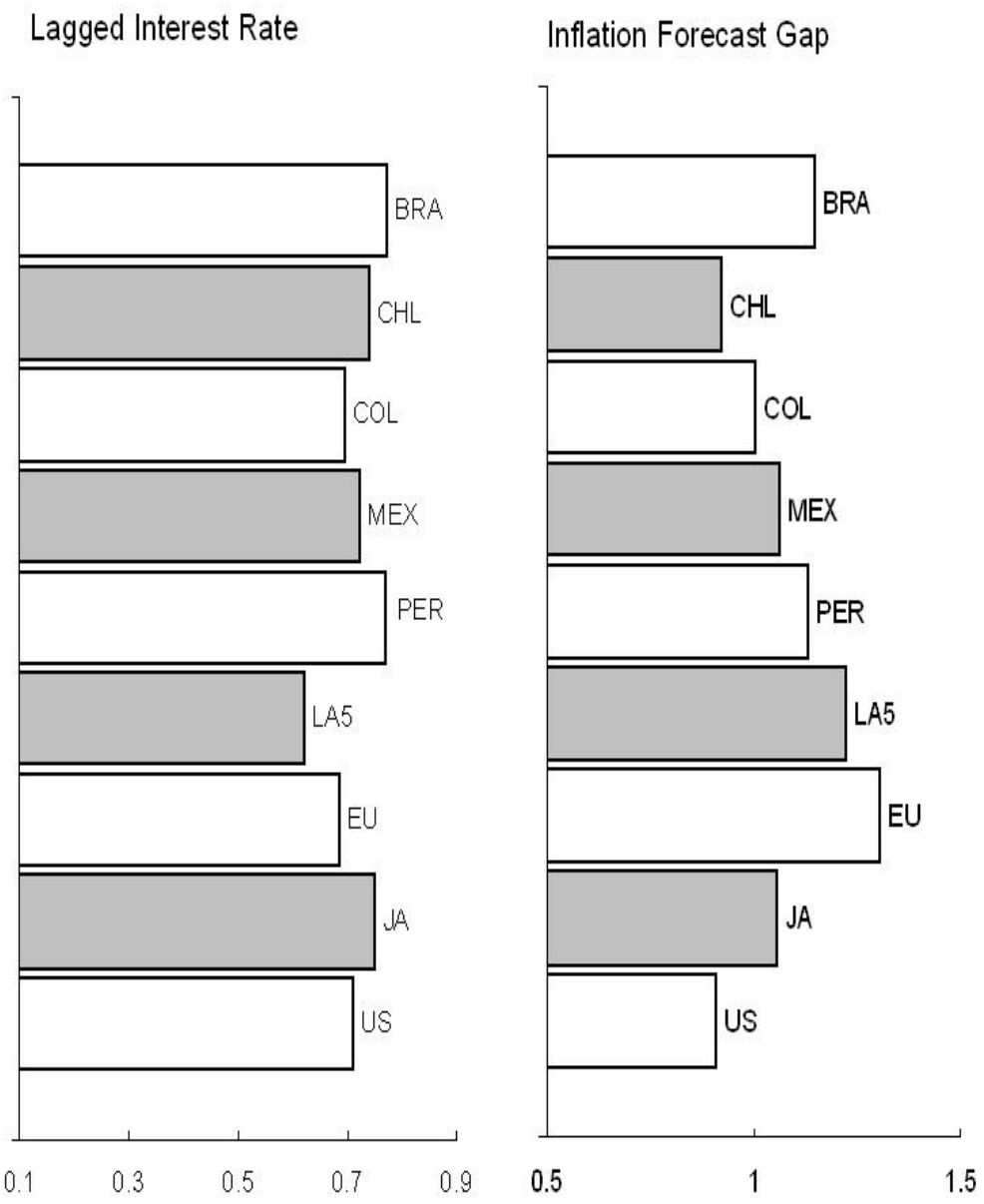

\section{Output Gap}

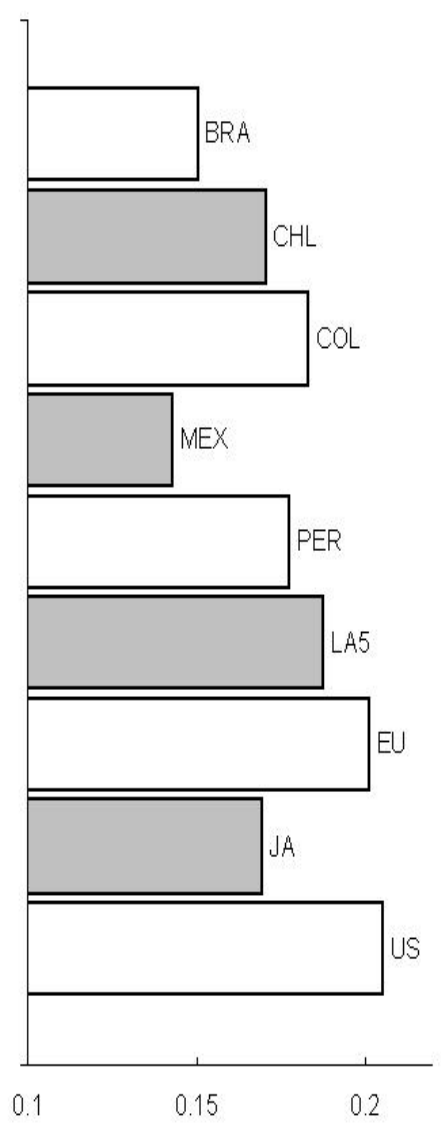


Table 2: Results from Posterior Parameters (Standard Deviation of Structural Shocks)

\begin{tabular}{|c|c|c|c|c|c|}
\hline & Prior distribution & Prior mean & Prior s.d. & Posterior mode & s.d. \\
\hline$\varepsilon_{l a 5}^{g^{\bar{Y}}}$ & invg & 0.100 & 0.0500 & 0.0747 & 0.0251 \\
\hline$\varepsilon_{\underline{l a} 5}^{\bar{Y}}$ & invg & 0.200 & 0.0500 & 0.3095 & 0.1446 \\
\hline $\begin{array}{l}\varepsilon_{l a 5}^{Z} \\
\varepsilon_{l a 5}^{\pi}\end{array}$ & $\begin{array}{l}\text { invg } \\
\text { invg }\end{array}$ & $\begin{array}{l}1.000 \\
1.000\end{array}$ & $\begin{array}{l}\text { Inf } \\
\text { Inf }\end{array}$ & $\begin{array}{l}5.3902 \\
2.4179\end{array}$ & $\begin{array}{l}0.9493 \\
0.3770\end{array}$ \\
\hline$\varepsilon_{l a 5}^{\frac{l a d}{R}}$ & invg & 0.500 & 0.0500 & 0.5376 & 0.0820 \\
\hline$\varepsilon^{R_{l a 5}-R_{u s}}$ & invg & 1.000 & Inf & 0.4591 & 0.1861 \\
\hline$\varepsilon_{l a 5}^{r s}$ & invg & 0.500 & Inf & 0.5871 & 0.1504 \\
\hline$\varepsilon_{l a 5}^{U}$ & invg & 0.100 & Inf & 0.0438 & 0.0164 \\
\hline$\varepsilon_{l a 5}^{g^{\bar{U}}}$ & invg & 0.100 & Inf & 0.0435 & 0.0162 \\
\hline$\varepsilon_{l a 5}^{u a s}$ & invg & 0.100 & Inf & 0.2143 & 0.0333 \\
\hline$\varepsilon_{l a 5}^{y}$ & invg & 0.300 & Inf & 0.2275 & 0.1440 \\
\hline
\end{tabular}


Table 3: Results from Posterior Parameters (Correlation of Structural Shocks)

\begin{tabular}{l|lcccc}
\hline \hline & Prior distribution & Prior mean & Prior s.d. & Posterior mode & s.d. \\
\hline$\varepsilon_{l a 5}^{\bar{Y}}, \varepsilon_{l a 5}^{\pi}$ & beta & 0.100 & 0.0300 & 0.0909 & 0.0289 \\
$\varepsilon_{l a 5}^{y}, \varepsilon_{l a 5}^{g^{Y}}$ & beta & 0.250 & 0.1000 & 0.2185 & 0.1042 \\
\hline \hline
\end{tabular}


Table 4: Root Mean Squared Errors

\begin{tabular}{|c|c|c|c|c|}
\hline & $1 \mathrm{Q}$ Ahead & 4 Q Ahead & 8 Q Ahead & 12 Q Ahead \\
\hline Output Gap LA5 $y_{l a 5}$ & 0.273 & 0.817 & 0.871 & 0.513 \\
\hline GDP Quarterly Growth at annual rates LA5 $4\left(Y_{l a 5}-Y_{l a 5,-1}\right)$ & 1.95 & 2.67 & 2.11 & 1.84 \\
\hline GDP Year-on-Year Growth LA5 $Y_{l a 5}-Y_{l a 5,-4}$ & 0.504 & 1.42 & 1.3 & 0.995 \\
\hline Unemployment Rate LA5 $U_{l a 5}$ & 0.266 & 0.411 & 0.372 & 0.287 \\
\hline CPI Year-on-Year Inflation LA5 $\pi 4_{l a 5}$ & 0.698 & 2.41 & 1.05 & 0.893 \\
\hline Short-term Interest Rate (RS) LA5 $r s_{l a 5}$ & 0.886 & 2.58 & 2.16 & 2.31 \\
\hline
\end{tabular}


Figure 5: Domestic demand shock
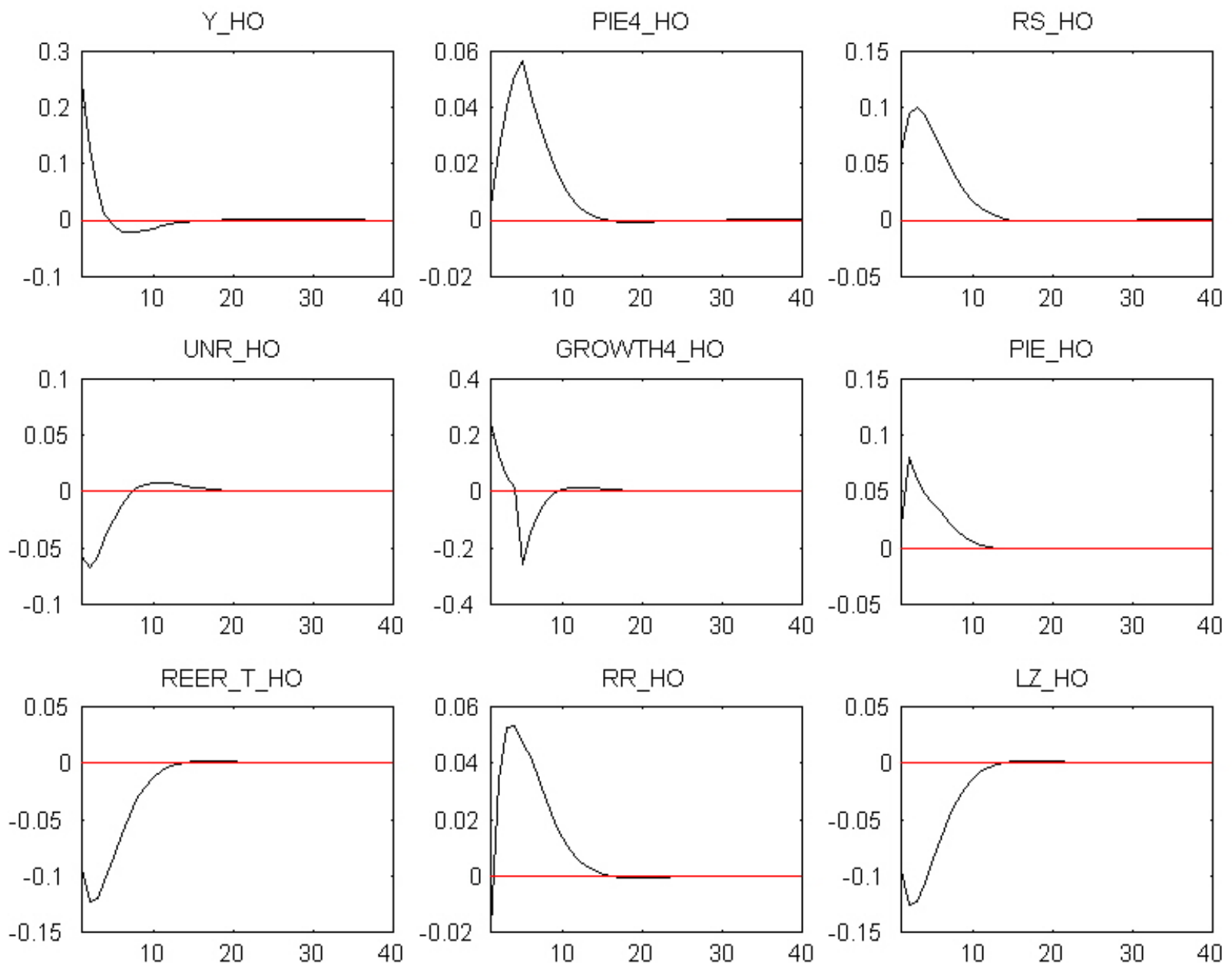
Figure 6: Domestic price shock
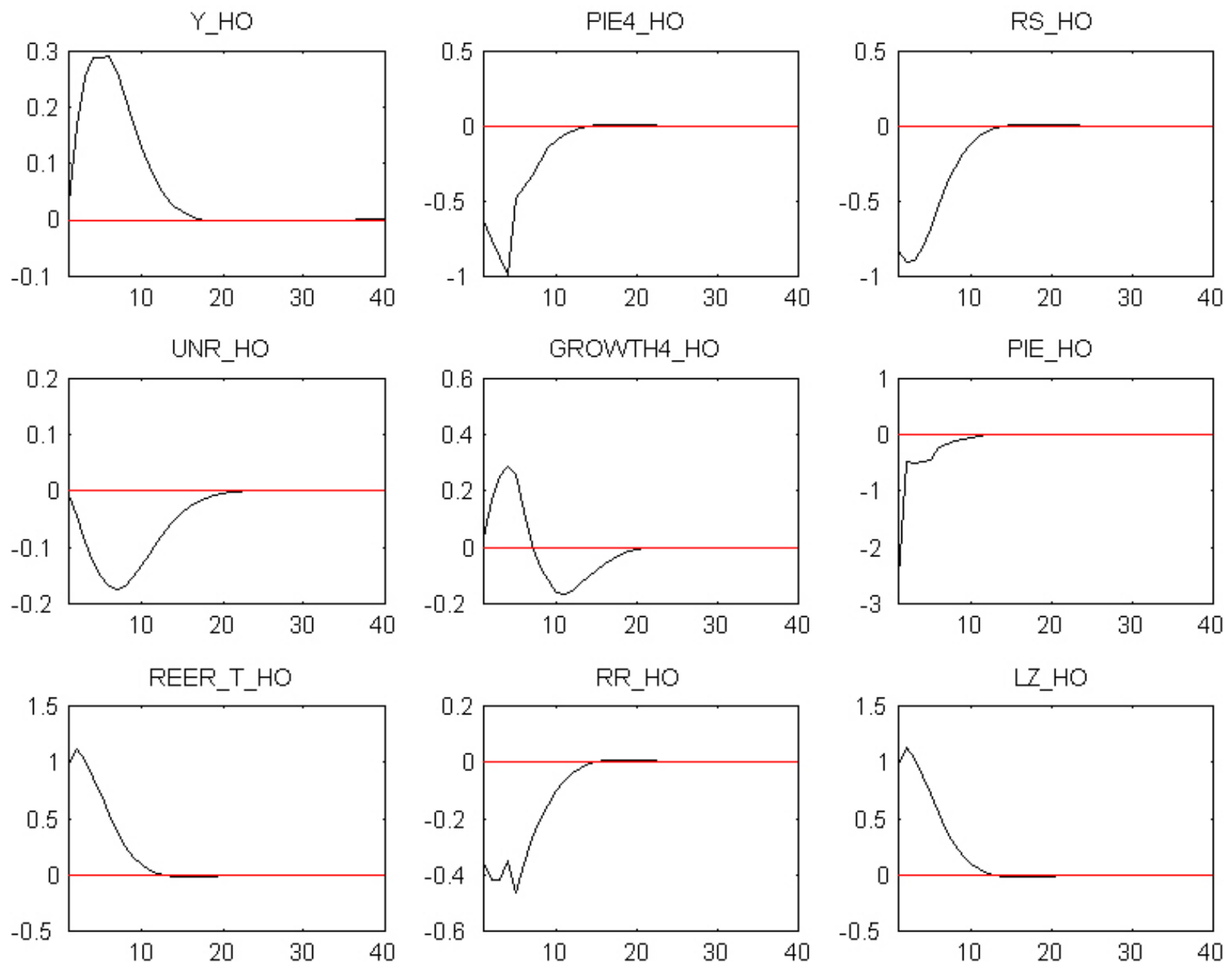
Figure 7: Demand shock in the US
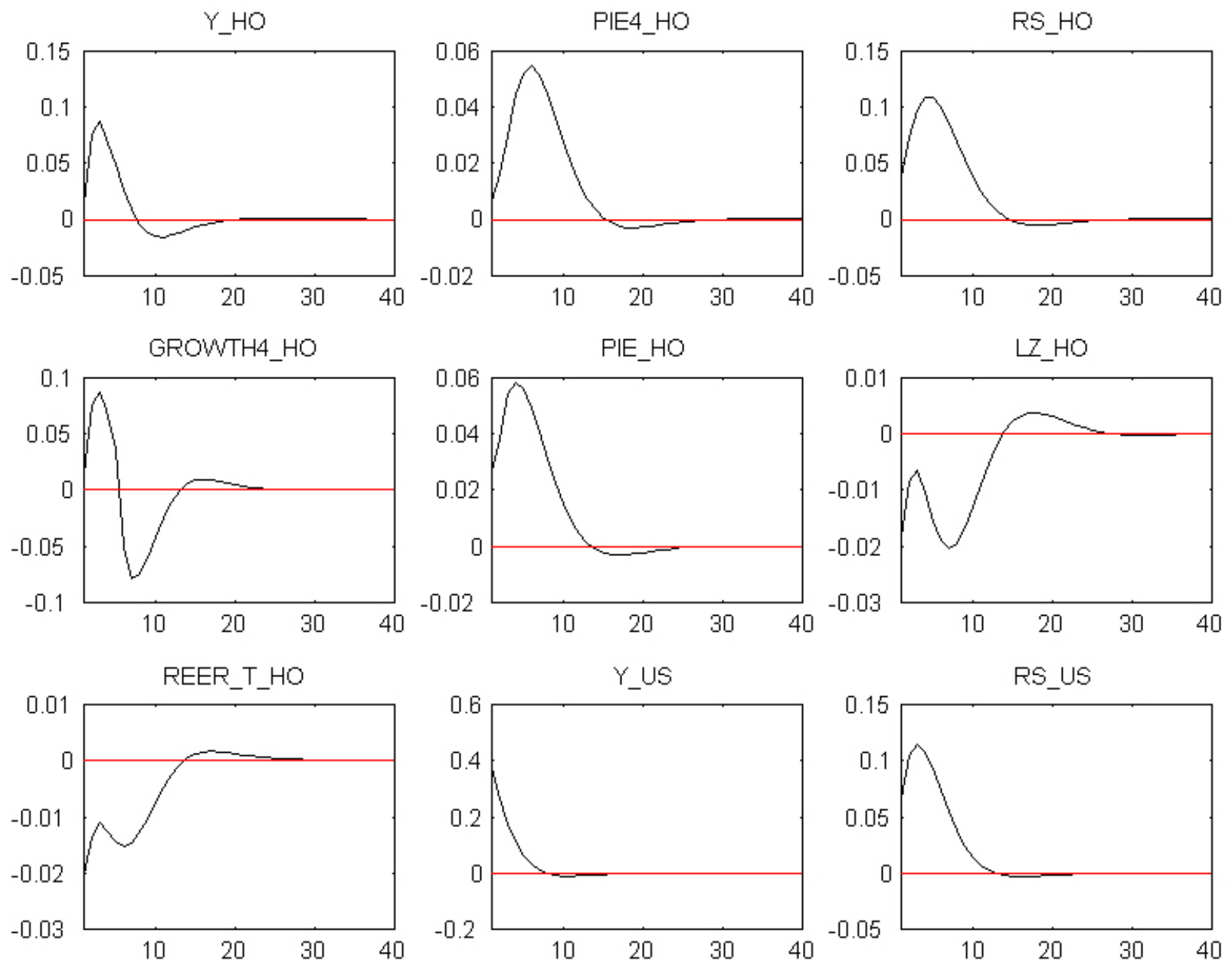
Figure 8: BLT shock in the US
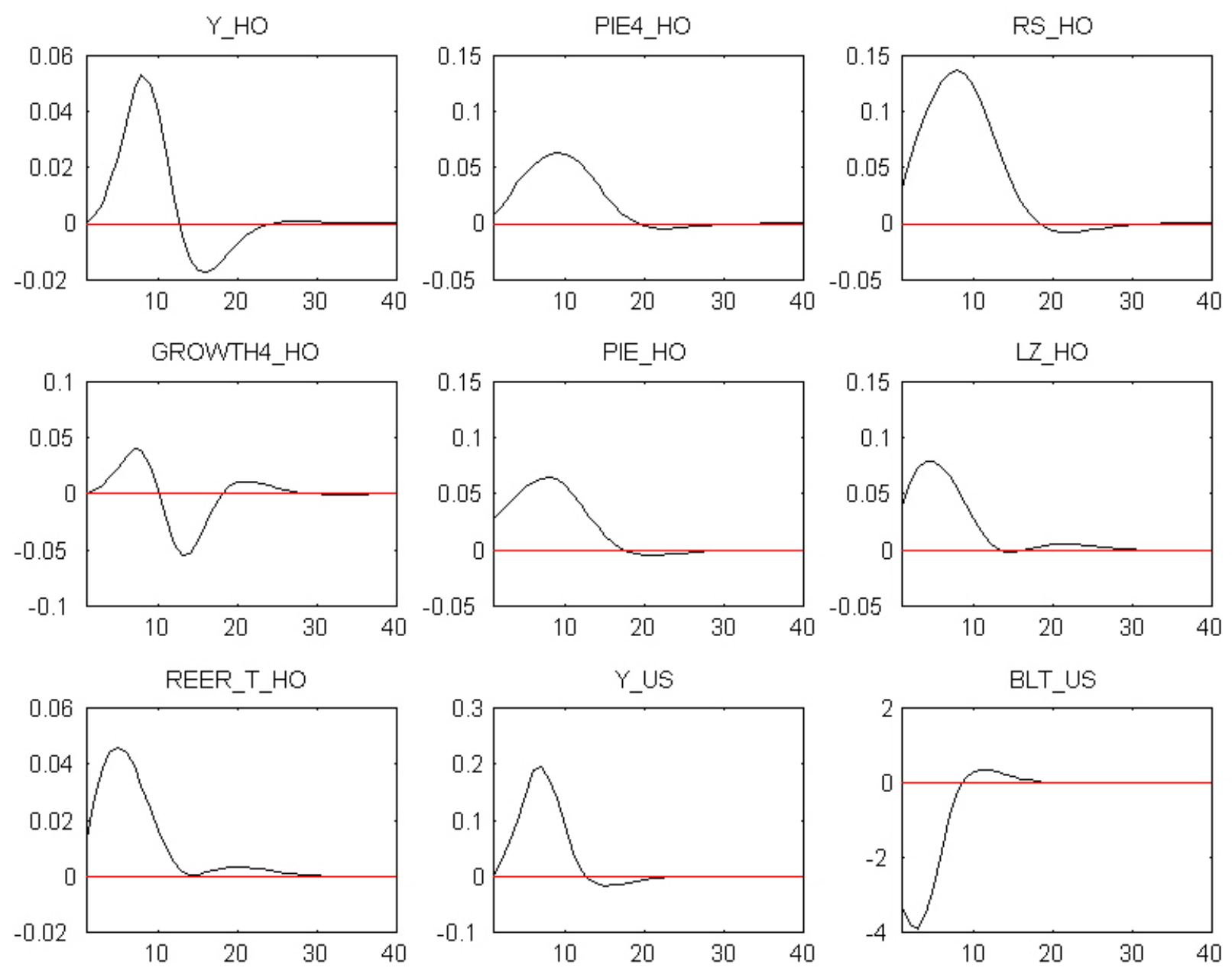
Figure 9: Historical Decomposition of Inflation 2004-08

(percentage points deviations from the estimated inflation target $1 /$ )
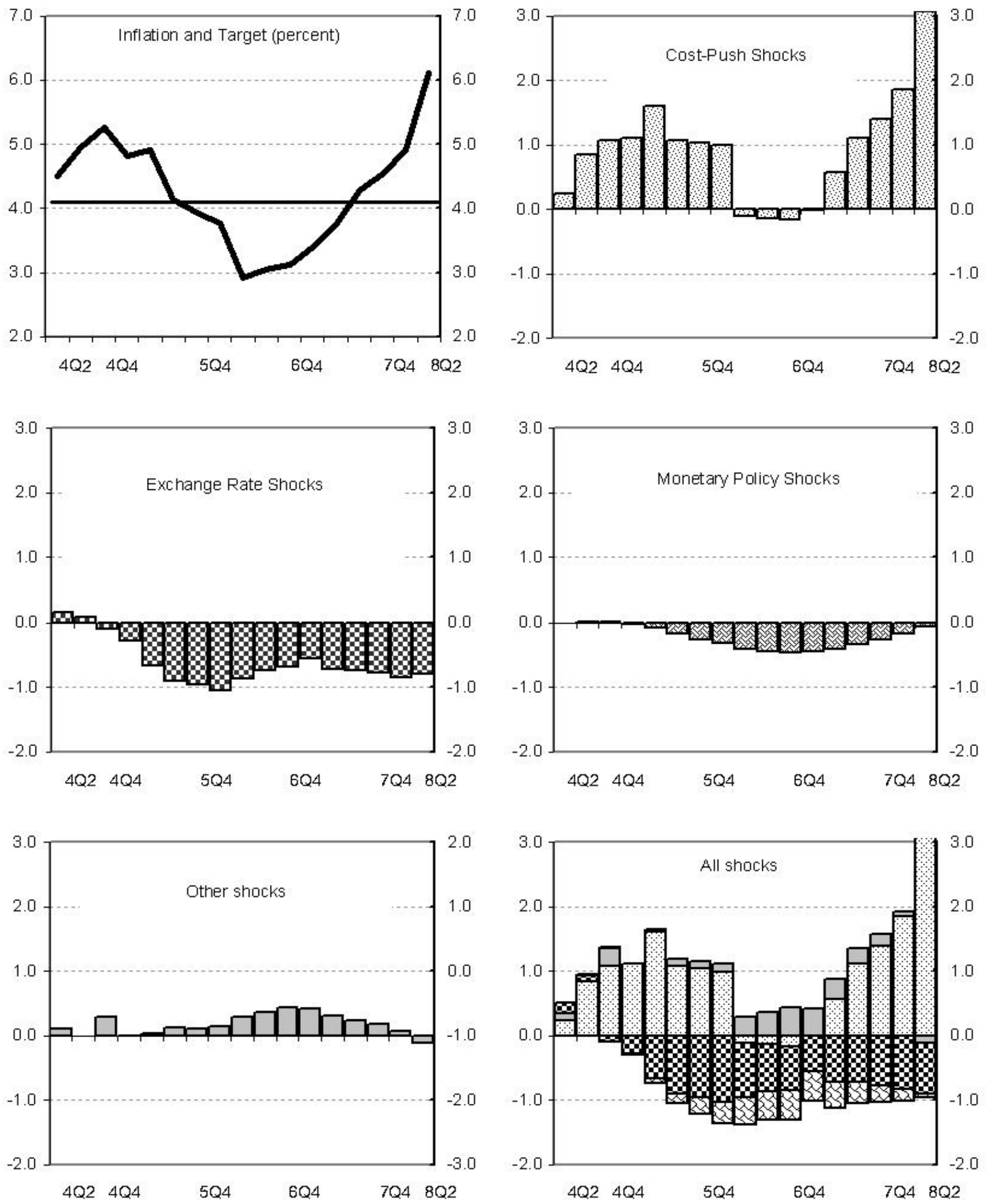